\title{
An improved non-iterative surface layer flux scheme for atmospheric stable stratification conditions
}

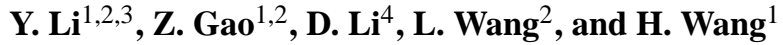 \\ ${ }^{1}$ Jiangsu Key Laboratory of Agriculture Meteorology, Collaborative Innovation Center on Forecast and Evaluation of \\ Meteorological Disasters, College of Applied Meteorology, Nanjing University of Information Science and Technology, \\ Nanjing, Jiangsu, China \\ ${ }^{2}$ State Key Laboratory of Atmospheric Boundary Layer Physics and Atmospheric Chemistry, Institute of Atmospheric \\ Physics, Chinese Academy of Sciences, Beijing, China \\ ${ }^{3}$ School of Energy and Environment, City University of Hong Kong, Hong Kong, China \\ ${ }^{4}$ Program of Atmospheric and Oceanic Sciences, Princeton University, Princeton, NJ 08540, USA
}

Correspondence to: Z. Gao (zgao@mail.iap.ac.cn)

Received: 29 October 2013 - Published in Geosci. Model Dev. Discuss.: 5 December 2013

Revised: 14 February 2014 - Accepted: 14 February 2014 - Published: 26 March 2014

\begin{abstract}
Parameterization of turbulent fluxes under stably stratified conditions has always been a challenge. Current surface fluxes calculation schemes either need iterations or suffer low accuracy. In this paper, a non-iterative scheme is proposed to approach the classic iterative computation results using multiple regressions. It can be applied to the full range of roughness status $10 \leq z / z_{0} \leq 10^{5}$ and $-0.5 \leq$ $\log \left(z_{0} / z_{0 h}\right) \leq 30$ under stable conditions $0<R i_{\mathrm{B}} \leq 2.5$. The maximum (average) relative errors for the turbulent transfer coefficients for momentum and sensible heat are $12 \%(1 \%)$ and $9 \%(1 \%)$, respectively.
\end{abstract}

\section{Introduction}

In weather or climate models, the earth's surface is the boundary that needs to be resolved physically (Chen and Dudhia, 2001). The condition of atmosphere aloft (e.g., wind, temperature and humidity) is highly dependent on the momentum, sensible heat and latent heat fluxes at surface. Currently, the exchanges of momentum and heat between the earth's surface and the atmosphere are usually calculated with various schemes based on Monin-Obukhov similarity theory (hereinafter MOST; Monin and Obukhov, 1954) in models. These schemes (e.g., Paulson, 1970; Businger et al., 1971; Dyer, 1974; Holtslag and De Bruin, 1988; Beljaars and Holtslag, 1991; Janjić, 1994; Launiainen, 1995;
Högström, 1996) are similar to each other, but the differences among them exist due to different observational data and/or mathematical solutions that were used in retrieving the schemes. One commonly used scheme is Businger-Dyer (BD) equation (Businger, 1966; Dyer, 1967). However, the BD equation suppresses fluxes under stable conditions too quickly and is not applicable when the Richardson number exceeds a critical value (Louis, 1979). Holtslag and De Bruin (1988) and Beljaars and Holtslag (1991) proposed alternative schemes that can be used under very stable conditions. With data collected in the field program CASES99 (Cooperative Atmosphere-Surface Exchange Study-99) (Poulos et al., 2002), Cheng and Brutsaert (2005, CB05 hereinafter) further provided a new scheme, and it is confirmed to perform better by later research (Guo and Zhang, 2007; Jiménez et al., 2012). Based on the measurements made during experiment SHEBA in Arctic and Halley 2003 experiment in Antarctica, Grachev et al. (2007) and Sanz Rodrigo and Anderson (2013) proposed different similarity functions, respectively. Through systematic mathematical analysis, Sharan and Kumar (2011) proved that similarity functions of CB05 and Grachev et al. (2007) were applicable in the whole stable stratification region. However, all of these studies are based on MOST, and application of MOST in very stable conditions is in doubt since it assumes that turbulence is continuous and stationary, while in very stable conditions turbulence is weak, sporadic and patchy (Sharan and Kumar, 


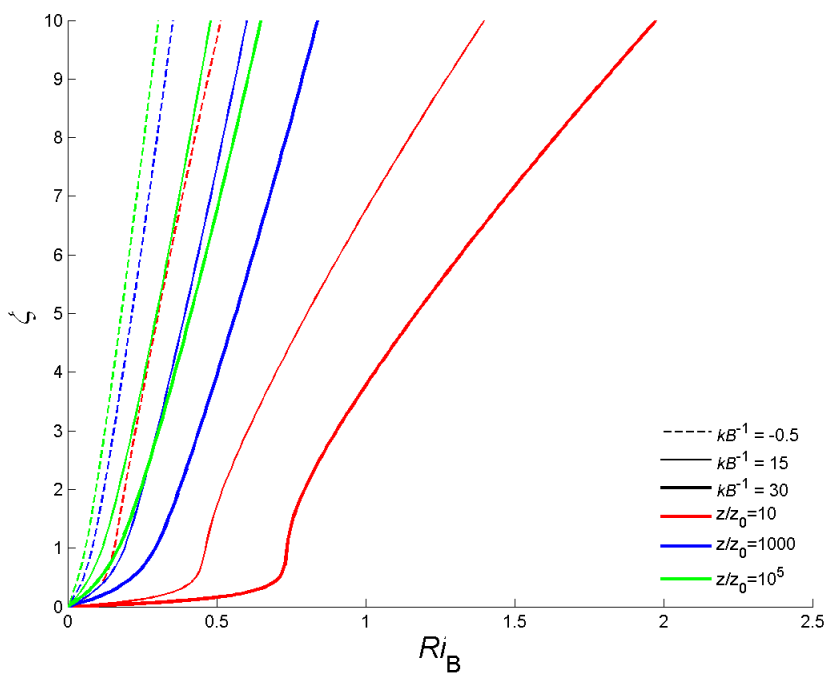

Fig. 1. The relationship between $R i_{\mathrm{B}}$ and $\zeta$ from the precise results of CB05.

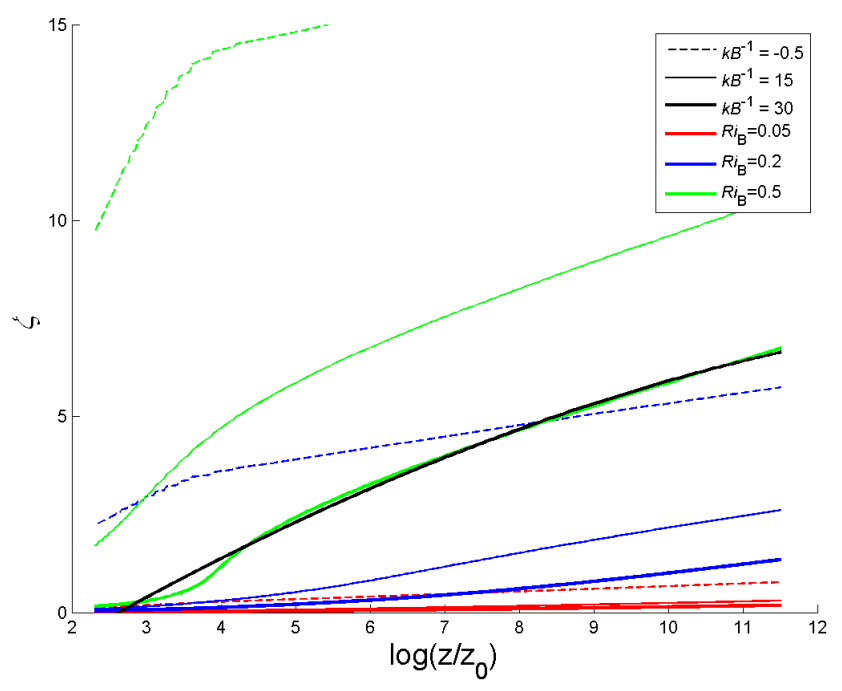

Fig. 2. The relationship between $\log \left(z / z_{0}\right)$ and $\zeta$ from the precise results of $\mathrm{CB} 05$. Black line indicates the cubic fit of curve $\mathrm{kB}^{-1}=$ 30 and $R i_{\mathrm{B}}=0.5$ with least square method.

2011). Grachev et al. (2013) indicate that the applicability of local MOST in stable conditions is limited by the inequalities, when both gradient and flux Richardson numbers are below their "critical values", about $0.20-0.25$. Further, MOST predicts that mean gradients of turbulence become independent of $z$ (height) in very stable conditions. Wyngaard and Coté (1972) first referred to this limit as " $z$-less stratification". BD equations follow this prediction, but CB05 and Grachev et al. (2007) do not. To avoid these holdbacks and self-correlation of MOST, Sorbjan (2010) and Sorbjan and Grachev (2010) discussed an alternative local scaling for the stable boundary layer (referred to as gradient-based scaling) when different universal functions were plotted versus the

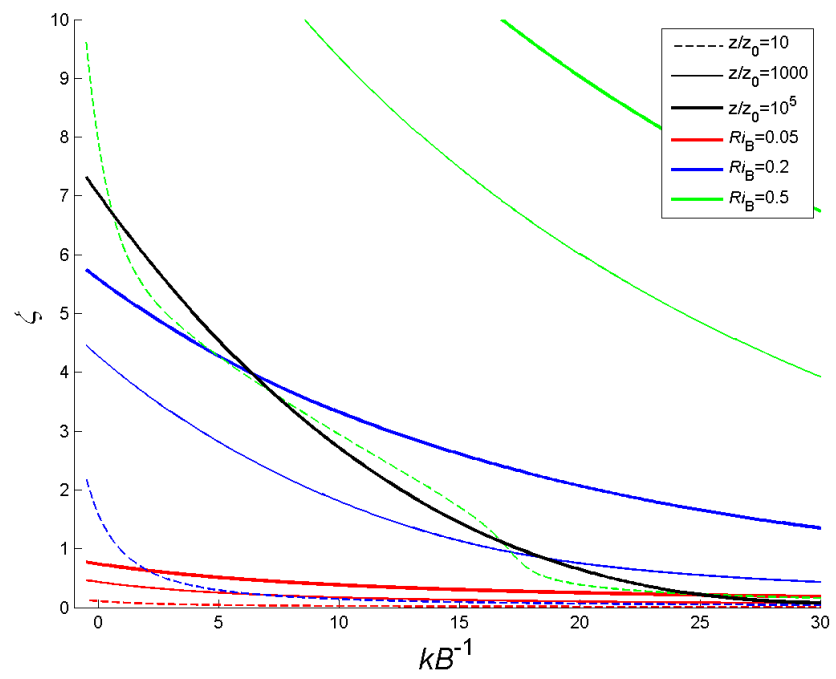

Fig. 3. The relationship between $\log \left(z / z_{0 h}\right)$ (i.e., $\left.\mathrm{kB}^{-1}\right)$ and $\zeta$ from the precise results of $\mathrm{CB} 05$. Black line indicates the cubic fit of curve $z / z_{0}=10$ and $R i_{\mathrm{B}}=0.5$ with least square method.

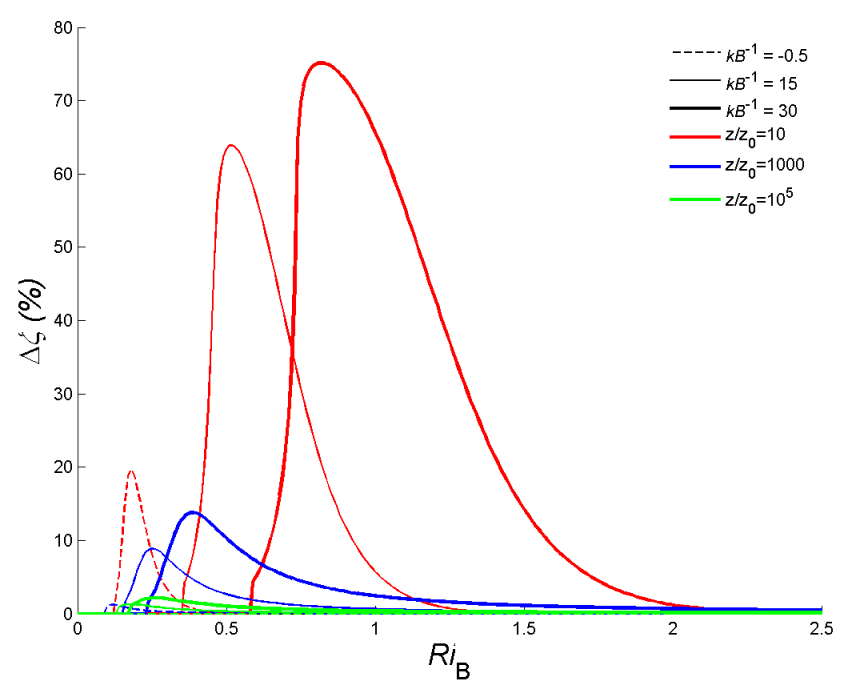

Fig. 4. Relative error after five steps of iteration with CB05 equations under certain $z_{0}$ and $z_{0 h}$ conditions.

gradient Richardson number instead of the Monin-Obukhov stability parameter.

Another critical issue regarding the flux calculation with MOST is the numerical iteration. Under unstable conditions, the iteration normally converges within five steps (Fairall et al., 1996). By taking advantage of a bulk Richardson number parameterization for an improved first guess (Grachev and Fairall, 1997), the iteration can be reduced to three steps (Fairall et al., 2003). In the Weather Research Forecasting (WRF) model (Skamarock et al., 2008) MM5 similarity surface module, the flux variables from the previous time step are used to calculate the fluxes at current time step, and such an approach can yield reasonable results (Jiménez et 


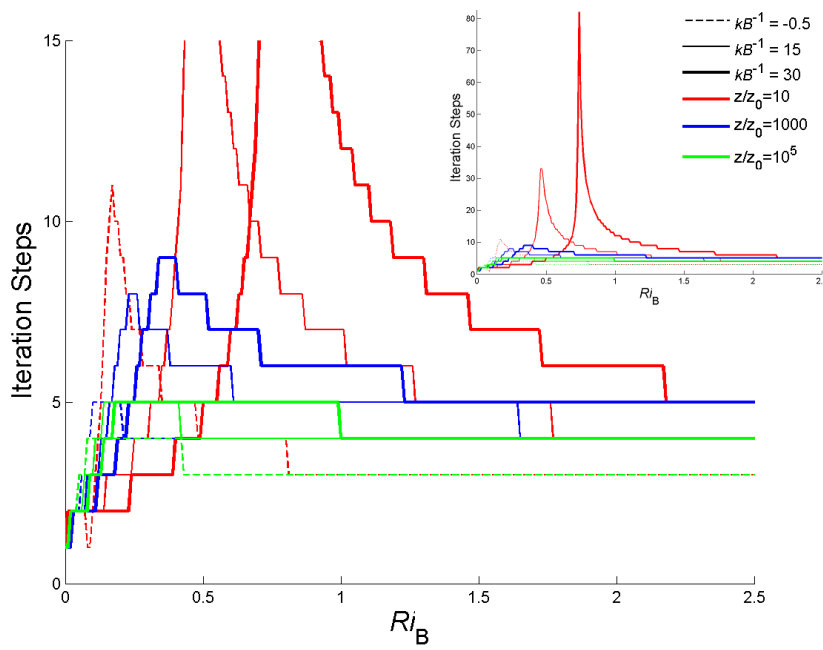

Fig. 5. Steps needed to converge into $5 \%$ relative error with $\mathrm{CB} 05$ equations under certain $z_{0}$ and $z_{0 h}$ conditions. The inset shows the whole perspective.

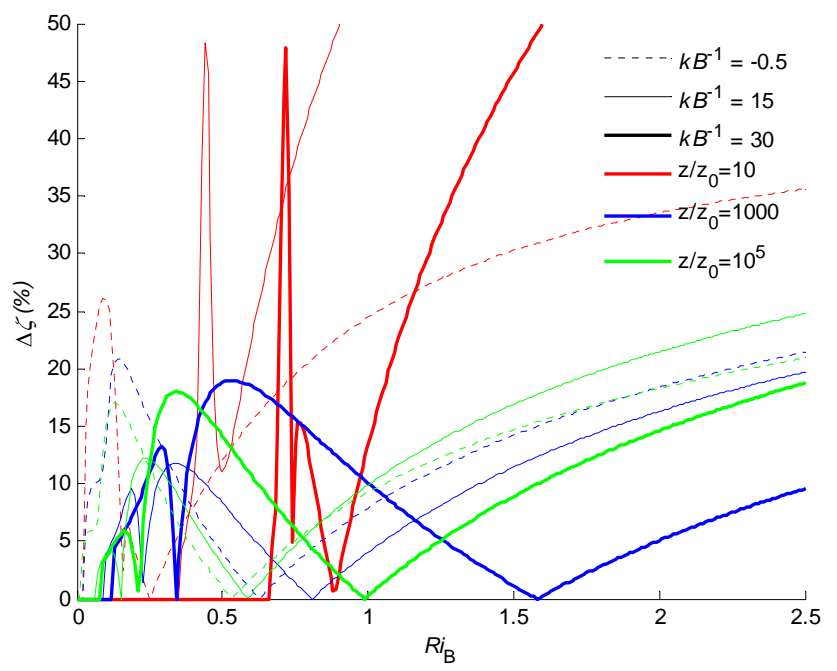

Fig. 6. Relative error with WRL12 equations.

al., 2012). On the other hand, under stable conditions, the flux calculation takes many more steps to converge and hence is time-consuming. To avoid the iteration process, a series of non-iterative schemes are proposed (e.g., Louis, 1979; Garratt, 1992; Launiainen, 1995; Song, 1998; De Bruin et al., 2000; Yang et al., 2001; Li et al., 2010), but they all fail to cover the full range of $-0.5 \leq \mathrm{kB}^{-1} \leq 30,10 \leq z / z_{0} \leq 10^{5}$ and $-5.0 \leq R i_{\mathrm{B}} \leq 2.5$, which is pointed out by Wouters et al. (2012, WRL12 hereinafter). Here $\mathrm{kB}^{-1}=\ln \left(z_{0} / z_{0 \mathrm{~h}}\right) . z$ is the reference height; and $z_{0}$ and $z_{0 h}$ are the aerodynamic and thermal roughness lengths, respectively. $R i_{\mathrm{B}}$ is the bulk Richardson number. Following WRL12, the condition that $R i_{\mathrm{B}}>2.5$ is not considered in this study, because it represents extremely stable stratification with very weak wind and little flux exchange. To calculate fluxes under all conditions,

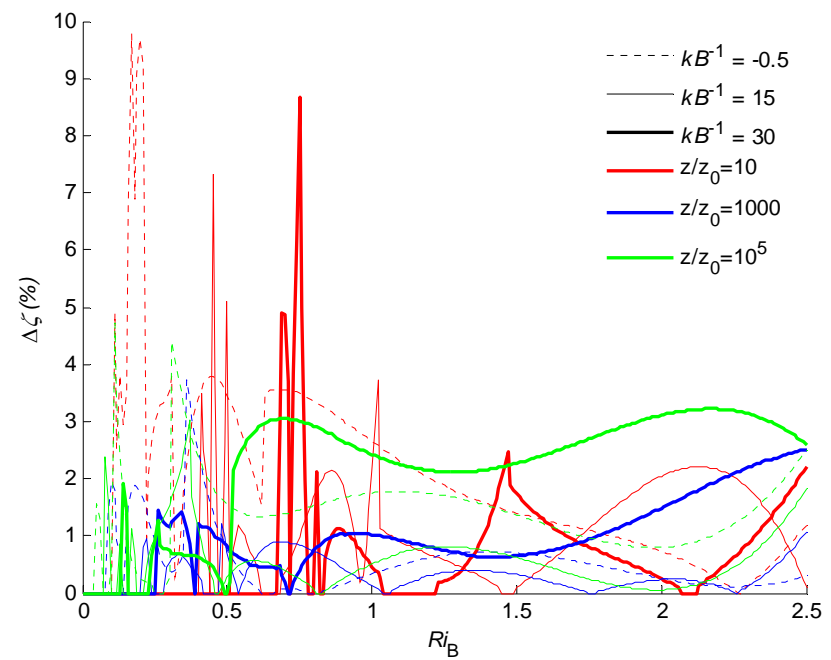

Fig. 7. Relative error with new equations.

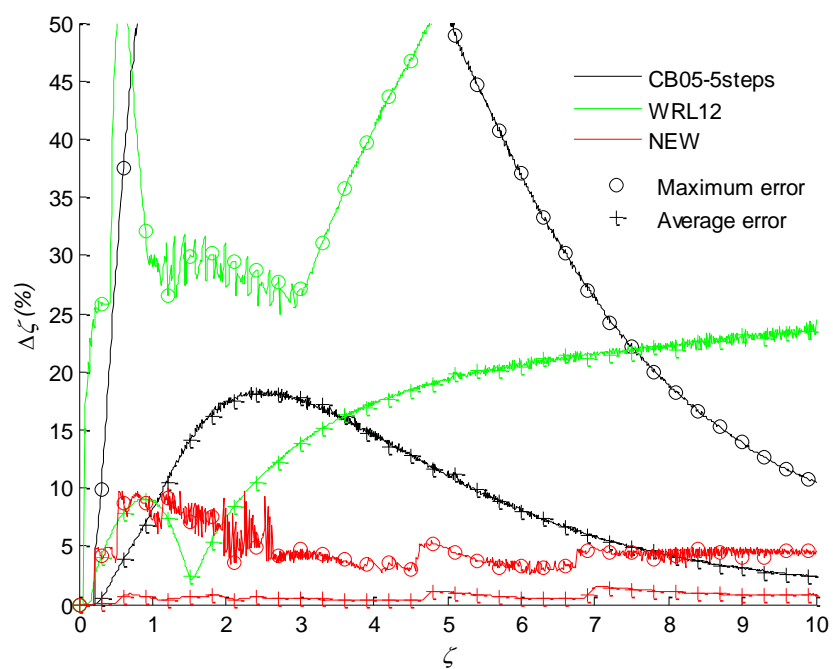

Fig. 8. Maximum (circles) and average (crosses) relative error of $\zeta$ for CB05 with five-step iteration (black lines), WRL12 (green lines) and the new scheme (red lines). Errors larger than $50 \%$ are not shown.

and also to include the roughness sublayer effect, WRL12 proposed an updated scheme based on the iterated results of CB05 under stable conditions. However, for a given $R i_{\mathrm{B}}$, WRL12 uses only one equation to cover the whole large range of $z / z_{0}$ and $\mathrm{kB}^{-1}$, which results in biases at some $z / z_{0}$ and $\mathrm{kB}^{-1}$ conditions. Therefore, to avoid the iteration process and keep the accuracy at the same time, the objective of this paper is to propose a group of equations that divide the calculation into eight regions according to $z_{0}$ and $z_{0 h}$ values. To compare with WRL12, and with the fact that CB05 equations are currently widely accepted, the new equations are also based on the iterated results of CB05 equations. Section 2 describes the calculation results from $\mathrm{CB} 05$ and 


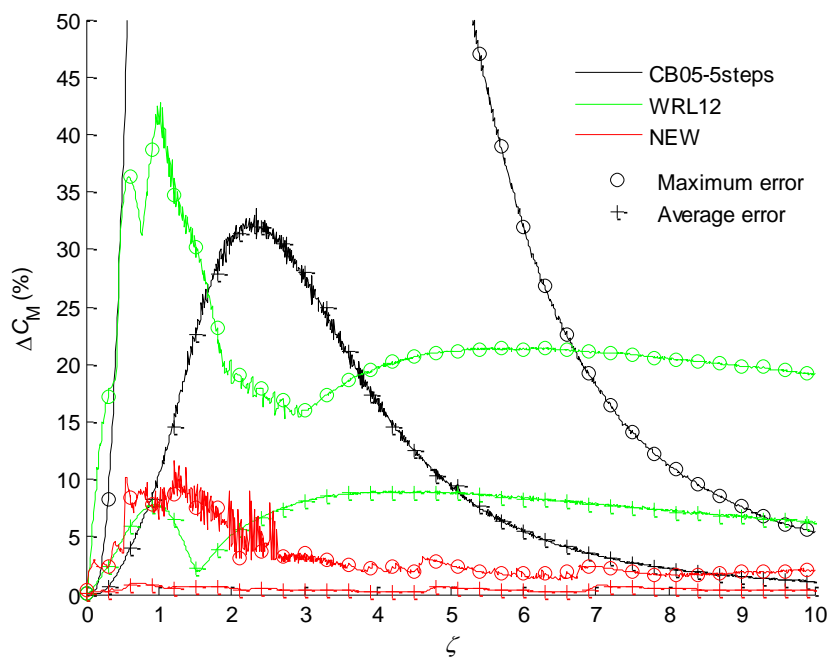

Fig. 9. Similar to Fig. 8 but for $C_{\mathrm{M}}$.

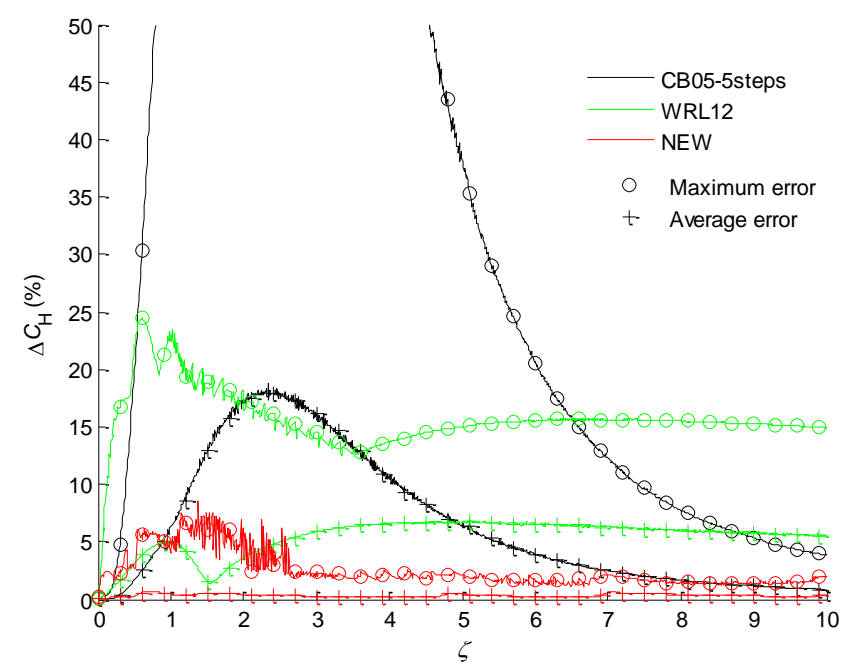

Fig. 10. Similar to Fig. 8 but for $C_{\mathrm{H}}$.

WRL12. Section 3 introduces the new equations, and Sect. 4 intercompares these schemes. Summary and conclusions are presented in Sect. 5.

\section{Revisiting CB05 and WRL12}

The momentum flux $\tau$ and sensible heat flux $H$ are defined as

$\tau \equiv \rho u_{*}^{2}$,

$H \equiv-\rho c_{p} u_{*} \theta_{*}$.

Here $u_{*}$ is the friction velocity, $\theta_{*}$ is the temperature scale, $\rho$ the air density, and $c_{p}$ the specific heat capacity at constant pressure. Based on MOST, the friction velocity $u_{*}$ and
Table 1. The eight regions divided by $z / z_{0}$ and $z_{0} / z_{0 h}$ values.

\begin{tabular}{lll}
\hline Region & $z / z_{0}$ & $z_{0} / z_{0 h}$ \\
\hline 1 & $10 \sim 160$ & $0.607 \sim 100$ \\
2 & $160 \sim 10^{5}$ & $0.607 \sim 100$ \\
3 & $10 \sim 80$ & $100 \sim 10^{7}$ \\
4 & $80 \sim 10^{5}$ & $100 \sim 10^{7}$ \\
5 & $10 \sim 40$ & $10^{7} \sim 10^{11}$ \\
6 & $40 \sim 10^{5}$ & $10^{7} \sim 10^{11}$ \\
7 & $10 \sim 40$ & $10^{11} \sim 1.07 \times 10^{13}$ \\
8 & $40 \sim 10^{5}$ & $10^{11} \sim 1.07 \times 10^{13}$ \\
\hline
\end{tabular}

temperature scale $\theta_{*}$ can be calculated by

$$
\begin{aligned}
u_{*}= & u k /\left[\ln \left(\frac{z}{z_{0}}\right)-\psi_{\mathrm{m}}\left(\frac{z}{L}\right)+\psi_{\mathrm{m}}\left(\frac{z_{0}}{L}\right)+\psi_{\mathrm{m}}^{*}\left(\frac{z}{L}, \frac{z}{z_{*}}\right)\right], \\
\theta_{*}= & \left(\theta-\theta_{0}\right) k /\left[\ln \left(\frac{z}{z_{0 h}}\right)-\psi_{\mathrm{h}}\left(\frac{z}{L}\right)+\psi_{\mathrm{h}}\left(\frac{z_{0 h}}{L}\right)\right. \\
& \left.+\psi_{\mathrm{h}}^{*}\left(\frac{z}{L}, \frac{z}{z_{*}}\right)\right] .
\end{aligned}
$$

Here $u$ and $\theta$ are the wind speed and potential temperature at the reference height $z . k$ is the von Kármán constant. $z_{*}$ is the roughness sublayer height. $\theta_{0}$ is the potential temperature at the height of $z_{0 h} . \psi_{\mathrm{m}}$ and $\psi_{\mathrm{h}}$ are the integrated stability functions for momentum and heat, respectively. $\psi_{\mathrm{m}}^{*}$ and $\psi_{\mathrm{h}}^{*}$ are the correction functions accounting for roughness sublayer effect. $L$ is the Obukhov length defined as

$L \equiv u_{*}^{2} \bar{\theta} /\left(\operatorname{kg} \theta_{*}\right)$.

$\psi_{\mathrm{m}}^{*}$ and $\psi_{\mathrm{h}}^{*}$ are given by De Ridder (2010):

$\psi_{\mathrm{m}, \mathrm{h}}^{*}\left(\frac{z}{L}, \frac{z}{z_{*}}\right)=\int_{z}^{\infty} \frac{\phi_{\mathrm{m}, \mathrm{h}}\left(\frac{z^{\prime}}{L}\right)}{z^{\prime}} e^{-\mu_{\mathrm{m}, \mathrm{h}} \frac{z^{\prime}}{z_{*}}} \mathrm{~d} z^{\prime}$.

$\mu_{\mathrm{m}}=2.59, \mu_{\mathrm{h}}=0.95$, and $\phi_{\mathrm{m}, \mathrm{h}}$ are the stability functions for momentum and heat. Following Sarkar and De Ridder (2010) and WRL12, $z_{*} / z_{0}=16.7$ is adopted in this study.

CB05 gives the form of $\phi_{\mathrm{m}, \mathrm{h}}$ and $\psi_{\mathrm{m}, \mathrm{h}}$ :

$\phi_{\mathrm{m}}=1+a \frac{\zeta+\zeta^{b}\left(1+\zeta^{b}\right)^{\frac{1-b}{b}}}{\zeta+\left(1+\zeta^{b}\right)^{\frac{1}{b}}}$,

$\phi_{\mathrm{h}}=1+c \frac{\zeta+\zeta^{d}\left(1+\zeta^{d}\right)^{\frac{1-d}{d}}}{\zeta+\left(1+\zeta^{d}\right)^{\frac{1}{d}}}$,

$\psi_{\mathrm{m}}=-a \ln \left(\zeta+\left(1+\zeta^{b}\right)^{\frac{1}{b}}\right)$ 
Table 2. The coefficients of Eq. (24).

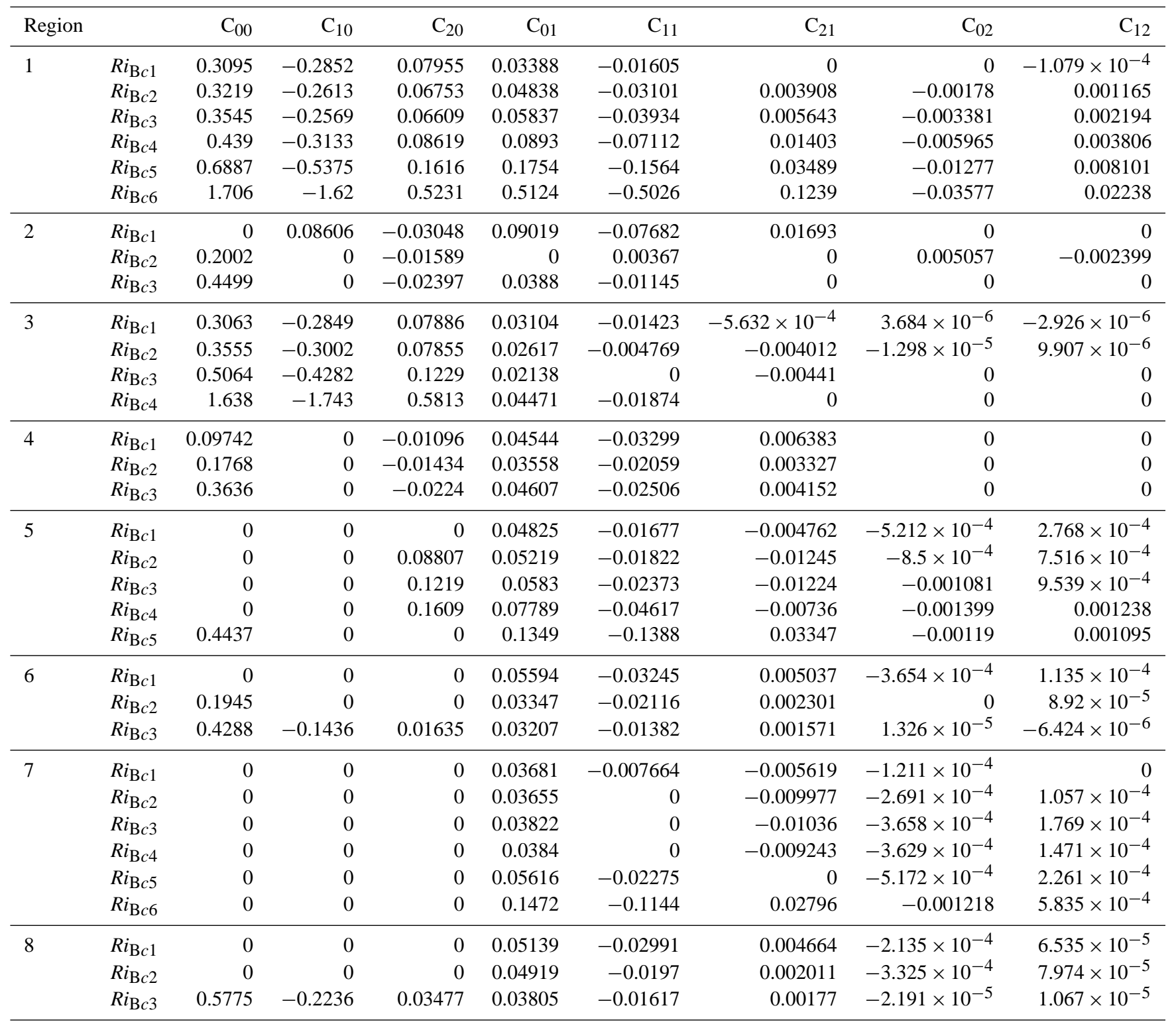

$\psi_{\mathrm{h}}=-c \ln \left(\zeta+\left(1+\zeta^{d}\right)^{\frac{1}{d}}\right)$.

Here $a=6.1, b=2.5, c=5.3$, and $d=1.1 . \zeta \equiv z / L$ is the stability parameter.

With Eqs. (3), (4), (5), and (6), $\phi_{\mathrm{m}, \mathrm{h}}$ and $\psi_{\mathrm{m}, \mathrm{h}}$ of CB05, fluxes can be calculated through iterations: with a first guess of $\zeta, u_{*}$ and $\theta_{*}$ can be calculated from Eqs. (3) and (4); then $\zeta$ again can be derived from Eq. (5). This procedure iterates until the results converge. The relationships of $\zeta \sim$ $R i_{\mathrm{B}}, \zeta \sim \ln \left(z / z_{0}\right)$, and $\zeta \sim \ln \left(z_{0} / z_{0 h}\right)$ from CB05 are shown in Figs. 1, 2 and 3, respectively. Conditions with $R i_{\mathrm{B}}=$ $0.05,0.2,0.5, z / z_{0}=10,1000,10^{5}$ and $\mathrm{kB}^{-1}=-0.5,15,30$ are plotted. However, due to the limitation of computational time in numerical weather and climate models, the calculation results after five steps are always taken to approximate the fluxes (e.g., MYJ and MYNN surface module in WRF model; Janjić, 1996; Nakanishi and Niino, 2006). It is found that with the first guess of $\zeta_{0}=R i_{\mathrm{B}} \frac{\left[\ln \left(z / z_{0}\right)\right]^{2}}{\ln \left(z / z_{0 h}\right)}$ and five steps of iteration, the results are still far away from the precise value. Figure 4 presents the relative error $\Delta \zeta$ for various $R i_{\mathrm{B}}$ with $z / z_{0}=10,1000,10^{5}$ and $\mathrm{kB}^{-1}=-0.5,15,30$. The relative error $\Delta \zeta$ that is calculated by Eq. (11) can exceed $70 \%$ under certain conditions.

$$
\begin{aligned}
& \Delta \zeta= \\
& \left\{\begin{array}{l}
\frac{\left|\zeta_{\text {(cal })}-\zeta_{\text {(precise) }}\right|}{\zeta_{\text {(precise) }}} \times 100 \%, \text { for }\left|\zeta_{\text {(cal) }}-\zeta_{\text {(precise) }}\right| \geq 0.01 \\
0, \text { for }\left|\zeta_{\text {(cal) }}-\zeta_{\text {(precise) }}\right|<0.01
\end{array}\right.
\end{aligned}
$$


Table 3. The coefficients of Eq. (23) for region 1.

\begin{tabular}{|c|c|c|c|c|c|c|c|}
\hline & \multicolumn{7}{|c|}{ Region 1} \\
\hline & Section 1 & Section 2 & Section 3 & Section 4 & Section 5 & Section 6 & Section 7 \\
\hline $\mathrm{C}_{000}$ & -1.134 & 0 & 0 & 0 & 0 & 0 & 0 \\
\hline $\mathrm{C}_{100}$ & 31.1 & 86.35 & -280.4 & 0 & 0 & -17.32 & -6.343 \\
\hline $\mathrm{C}_{200}$ & -71.16 & 0 & 3235 & 0 & 0 & 8.773 & 7.66 \\
\hline $\mathrm{C}_{300}$ & 227.4 & 0 & -6165 & 0 & 0 & 0 & -0.7661 \\
\hline $\mathrm{C}_{001}$ & -0.2094 & -11.53 & -10.64 & 0 & 0 & 0 & 0.0125 \\
\hline $\mathrm{C}_{101}$ & 3.293 & 194.9 & 193.8 & 0 & 1.113 & 0 & -2.203 \\
\hline $\mathrm{C}_{201}$ & -20.11 & -975.4 & -1194 & -12.37 & -97.56 & 0 & 0.8896 \\
\hline $\mathrm{C}_{301}$ & 14.42 & 1472 & 2161 & 0 & 159.4 & 0 & -0.1273 \\
\hline $\mathrm{C}_{002}$ & 0.1476 & -2.535 & -4.603 & 0 & 0 & 1.919 & -0.00827 \\
\hline $\mathrm{C}_{102}$ & -0.07325 & 28.24 & 52.02 & 11.99 & 16.33 & 0 & 0.3327 \\
\hline $\mathrm{C}_{202}$ & 0.5627 & -61.13 & -110.7 & -15.63 & -25.67 & 0.2679 & -0.04613 \\
\hline $\mathrm{C}_{003}$ & -0.01178 & -0.2378 & -0.5367 & -0.3157 & -0.6447 & -0.2892 & 0 \\
\hline $\mathrm{C}_{103}$ & 0.0218 & 0.7405 & 1.503 & 0.2948 & 0.9718 & 0 & -0.04968 \\
\hline $\mathrm{C}_{010}$ & 1.405 & 13.6 & 30.26 & 0 & 6.821 & 10.27 & 7.513 \\
\hline $\mathrm{C}_{110}$ & -32.47 & -316.2 & -314.9 & 0 & -57.13 & 0 & 0 \\
\hline $\mathrm{C}_{210}$ & 46.59 & 1067 & 186 & -108.1 & 227.3 & 0 & -4.799 \\
\hline $\mathrm{C}_{310}$ & -38.25 & -1494 & 0 & 317.8 & -244 & 0 & 0.5598 \\
\hline $\mathrm{C}_{011}$ & -0.2286 & 8.023 & 9.038 & 0 & 0.9287 & -3.457 & -1.612 \\
\hline $\mathrm{C}_{111}$ & -1.097 & -91.31 & -87.06 & -12.52 & -17.88 & -1.617 & 0 \\
\hline $\mathrm{C}_{211}$ & -0.3394 & 213.7 & 198.6 & 0 & 34.41 & 0 & 0 \\
\hline $\mathrm{C}_{012}$ & 0 & 1.035 & 1.529 & 0 & 0.319 & -0.07536 & 0.4666 \\
\hline $\mathrm{C}_{112}$ & 0 & -5.072 & -7.439 & -1.025 & -2.452 & 0 & 0.0605 \\
\hline $\mathrm{C}_{013}$ & 0 & 0.03622 & 0.07369 & 0.04669 & 0.08583 & 0.05146 & -0.01808 \\
\hline $\mathrm{C}_{020}$ & 0 & -4.699 & -10.71 & -1.896 & -2.195 & -3.108 & 0 \\
\hline $\mathrm{C}_{120}$ & 10.71 & 97.46 & 122.1 & 28.39 & 22.21 & 7.948 & 2.442 \\
\hline $\mathrm{C}_{220}$ & 0 & -152.4 & -76.91 & -14.19 & -31.44 & -2.985 & 0.1584 \\
\hline $\mathrm{C}_{021}$ & 0 & -1.704 & -2.035 & 0 & -0.1355 & 0.8751 & 0 \\
\hline $\mathrm{C}_{121}$ & 0 & 9.069 & 8.248 & 2.214 & 1.976 & 0.3139 & -0.04377 \\
\hline $\mathrm{C}_{022}$ & 0 & -0.09576 & -0.1263 & -0.01472 & -0.04636 & -0.05131 & -0.0694 \\
\hline $\mathrm{C}_{030}$ & -0.007485 & 0.4446 & 1.015 & 0.3069 & 0.1708 & 0.2598 & -0.1675 \\
\hline $\mathrm{C}_{130}$ & -0.9671 & -7.991 & -10.96 & -3.635 & -1.623 & -0.8513 & -0.2181 \\
\hline $\mathrm{C}_{031}$ & 0.003402 & 0.1138 & 0.1426 & -0.008769 & 0 & -0.05427 & 0.05052 \\
\hline
\end{tabular}

where $\zeta_{\text {(cal) }}$ is the calculation result, and $\zeta_{\text {(precise) }}$ is the precise result from the ultimate iteration of CB05 (when $\left|\zeta_{(n+1)}-\zeta_{(n)}\right|<0.1 \% \zeta_{(n)}, \zeta_{(n)}$ is adopted as $\zeta_{(\text {precise) }}$, and here $n$ indicates the iteration step). Figure 5 shows the steps needed to converge into $5 \%$ relative error with $\mathrm{CB} 05$ equations for various $R i_{\mathrm{B}}$ with $z / z_{0}=10,1000,10^{5}$ and $\mathrm{kB}^{-1}=$ $-0.5,15,30$. It shows that when $R i_{\mathrm{B}}=0.74, z / z_{0}=10$ and $\mathrm{kB}^{-1}=30$, more than 80 steps of iteration are needed to reduce the calculation error within $5 \%$. The iteration takes more steps to converge when there is a larger aerodynamic roughness length $z_{0}$ and a smaller thermal roughness length $z_{0 h}$, which is common over an urban surface (Sugawara and Narita, 2009). When $z / z_{0}=10$ and $\mathrm{kB}^{-1}=30$, the largest error can reach $75 \%$ after five-step iteration (Fig. 4) and 82 steps are needed for the results to converge (Fig. 5). However, when $z / z_{0}$ becomes large, for example $z / z_{0}=10^{5}$ (i.e., a representative value for a smooth sea surface), five steps are enough for the results to be within $5 \%$ error under all $\mathrm{kB}^{-1}$ and $R i_{\mathrm{B}}$ conditions (Fig. 5).

To avoid the iteration, and based on CB05's iteration results, WRL12 proposed the following set of equations:

$$
\begin{aligned}
\zeta_{t}= & -0.316-0.515 e^{-L_{0 \mathrm{H}}}+25.8 e^{-2 L_{0 \mathrm{H}}}+4.36 L_{0 \mathrm{H}}^{-1} \\
& -6.39 L_{0 \mathrm{H}}^{-2}+0.834 \log \left(L_{0 \mathrm{M}}\right)-0.0267 \log ^{2}\left(L_{0 \mathrm{M}}\right), \\
R i_{\mathrm{B}, t}=\zeta_{t} \frac{L_{0 \mathrm{H}}^{*}+S_{0 \mathrm{H}}^{*} \beta_{\mathrm{H}} \zeta_{t}}{\left(L_{0 \mathrm{M}}^{*}+S_{0 \mathrm{M}}^{*} \beta_{\mathrm{M}} \zeta_{t}\right)^{2}} & \\
\zeta= & \frac{-L_{0 \mathrm{M}}^{*}}{S_{0 \mathrm{M}}^{*} \beta_{\mathrm{M}}}-\frac{B C}{4\left(S_{0 \mathrm{M}}^{*} \beta_{\mathrm{M}}\right)^{3}\left(B^{2}+|\mathrm{Cr}|\right)} \\
& +\frac{B-\sqrt{B^{2}+\mathrm{Cr}}+\frac{B \mathrm{Cr}}{2\left(B^{2}+|\mathrm{Cr}|\right)}}{2\left(S_{0 \mathrm{M}}^{*} \beta_{\mathrm{M}}\right)^{3} r},\left(\text { for } R i_{\mathrm{B}} \leq R i_{\mathrm{B}, t}\right),
\end{aligned}
$$


Table 4. Similar to Table 3, but for region 2.

\begin{tabular}{|c|c|c|c|c|}
\hline & \multicolumn{4}{|c|}{ Region 2} \\
\hline & Section 1 & Section 2 & Section 3 & Section 4 \\
\hline $\mathrm{C}_{000}$ & 0 & 0 & 0 & 0 \\
\hline $\mathrm{C}_{100}$ & 0 & 0 & 41.53 & 0 \\
\hline $\mathrm{C}_{200}$ & 0 & 0 & 0 & 0 \\
\hline $\mathrm{C}_{300}$ & 0 & 0 & 0 & 0 \\
\hline $\mathrm{C}_{001}$ & 0 & 0 & -1.616 & -2.57 \\
\hline $\mathrm{C}_{101}$ & 0 & -12.35 & 0 & -2.91 \\
\hline $\mathrm{C}_{201}$ & 0 & 0 & 0 & 0 \\
\hline $\mathrm{C}_{301}$ & 0 & 0 & 0 & 0 \\
\hline $\mathrm{C}_{002}$ & 0 & 0 & 0 & 0.874 \\
\hline $\mathrm{C}_{102}$ & 0 & 0.5183 & 0 & 0.3377 \\
\hline $\mathrm{C}_{202}$ & 0 & 0 & 0 & 0 \\
\hline $\mathrm{C}_{003}$ & 0 & 0 & 0 & -0.002092 \\
\hline $\mathrm{C}_{103}$ & 0 & 0 & 0 & -0.01343 \\
\hline $\mathrm{C}_{010}$ & 0.9996 & 0.8247 & 0 & 7.453 \\
\hline $\mathrm{C}_{110}$ & 0 & 0 & 15.82 & 5.4 \\
\hline $\mathrm{C}_{210}$ & 56.57 & 112.5 & -27.37 & -1.623 \\
\hline $\mathrm{C}_{310}$ & 0 & 0 & 0 & 0.1999 \\
\hline $\mathrm{C}_{011}$ & -0.1456 & -0.09054 & 0 & 0 \\
\hline $\mathrm{C}_{111}$ & 0 & 0 & 0 & 0.4753 \\
\hline $\mathrm{C}_{211}$ & -12.1 & -2.249 & 0 & 0 \\
\hline $\mathrm{C}_{012}$ & 0 & 0.01653 & 0 & -0.2047 \\
\hline $\mathrm{C}_{112}$ & 0.1303 & 0 & 0.02288 & -0.02581 \\
\hline $\mathrm{C}_{013}$ & 0 & 0 & 0 & 0 \\
\hline $\mathrm{C}_{020}$ & 0 & 0 & 0.1062 & -0.9043 \\
\hline $\mathrm{C}_{120}$ & 0.295 & 0.8326 & -0.9992 & -0.3386 \\
\hline $\mathrm{C}_{220}$ & 0 & -9.554 & 1.56 & 0.04556 \\
\hline $\mathrm{C}_{021}$ & 0.005508 & 0 & 0 & 0.04682 \\
\hline $\mathrm{C}_{121}$ & -0.0359 & 0.07022 & 0 & -0.01924 \\
\hline $\mathrm{C}_{022}$ & $4.067 \times 10^{-4} \times 10^{-4}$ & -0.001333 & 0 & 0.01217 \\
\hline $\mathrm{C}_{030}$ & 0 & 0 & 0 & 0.03944 \\
\hline $\mathrm{C}_{130}$ & 0 & 0 & 0 & 0.006516 \\
\hline $\mathrm{C}_{031}$ & 0 & 0 & 0 & -0.003571 \\
\hline
\end{tabular}

$\zeta=\zeta_{t}+D\left(\zeta_{t}\right)\left(R i_{\mathrm{B}}-R i_{\mathrm{B}, t}\right),\left(\right.$ for $\left.R i_{\mathrm{B}}>R i_{\mathrm{B}, t}\right)$

$D\left(\zeta_{t}\right)=\frac{\left(L_{0 \mathrm{M}}^{*}+S_{0 \mathrm{M}}^{*} \beta_{\mathrm{M}} \zeta_{t}\right)^{3}}{L_{0 \mathrm{M}}^{*} L_{0 \mathrm{H}}^{*}+\zeta_{t}\left(2 S_{0 \mathrm{H}}^{*} \beta_{\mathrm{H}} L_{0 \mathrm{M}}^{*}-S_{0 \mathrm{M}}^{*} \beta_{\mathrm{M}} L_{\left.0 \mathrm{H}^{*}\right)}\right.}$

where

$L_{0 i}=\log \left(z / z_{0 i}\right),(i$ stands for $\mathrm{M}$ or $\mathrm{H})$,

$L_{0 i}^{*}=L_{0 i}+\frac{1}{\lambda} \log \left(1+\frac{\lambda}{\mu_{i} \frac{z}{z_{*}}}\right) e^{-\mu_{i} \frac{z}{z_{*}}}$,

( $i$ stands for $\mathrm{M}$ or $\mathrm{H}$ ),

$r=R i_{\mathrm{B}}-S_{0 \mathrm{H}}^{*} \beta_{\mathrm{H}} /\left(S_{0 \mathrm{M}}^{*} \beta_{\mathrm{M}}\right)^{2}$,
$B=S_{0 \mathrm{M}}^{*} \beta_{\mathrm{M}} L_{0 \mathrm{H}}^{*}-2 S_{0 \mathrm{H}}^{*} \beta_{\mathrm{H}} L_{0 \mathrm{M}}^{*}$,

$C=4\left(S_{0 \mathrm{M}}^{*} \beta_{\mathrm{M}}\right)^{2} L_{0 \mathrm{M}}^{*}\left(S_{0 \mathrm{H}}^{*} \beta_{\mathrm{H}} L_{0 \mathrm{M}}^{*}-S_{0 \mathrm{M}}^{*} \beta_{\mathrm{M}} L_{0 \mathrm{H}}^{*}\right)$,

$S_{0 i}^{*}=1-z_{0 i} / z+\left(1+\frac{v}{\mu_{i} \frac{z}{z_{*}}}\right) \frac{1}{\lambda} \log \left(1+\frac{\lambda}{\mu_{i} \frac{z}{z_{*}}}\right) e^{-\mu_{i} \frac{z}{z_{*}}}$,

where $\lambda=1.5, v=0.5, \beta_{\mathrm{M}}=4.76+7.03 z_{0} / z+0.24 z_{0 h} / z_{0}$ and $\beta_{\mathrm{H}}=5$. First, $R i_{\mathrm{B}, t}$ is calculated from Eqs. (12) and (13), and then $\zeta$ can be derived from Eqs. (14) or (15). Figure 6 presents the relative error of $\zeta$ with WRL12 equations compared with iterated results of $\mathrm{CB} 05$ for various $R i_{\mathrm{B}}$ with $z / z_{0}=10,1000,10^{5}$ and $\mathrm{kB}^{-1}=-0.5,15,30$. It shows that the relative error of WRL12 exceeds $20 \%$ when $R i_{\mathrm{B}}$ is small, and exceeds $50 \%$ when $R i_{\mathrm{B}}$ becomes large. 
Table 5. Similar to Table 3, but for region 3.

\begin{tabular}{|c|c|c|c|c|c|}
\hline & & & Region 3 & & \\
\hline & Section 1 & Section 2 & Section 3 & Section 4 & Section 5 \\
\hline $\mathrm{C}_{000}$ & 2.001 & 0 & -68.85 & -1.514 & 0 \\
\hline $\mathrm{C}_{100}$ & -0.7876 & 0 & 756.9 & 0 & 0 \\
\hline $\mathrm{C}_{200}$ & 0 & 0 & -1100 & 0 & 0 \\
\hline $\mathrm{C}_{300}$ & 60.42 & 368.9 & 0 & 19.63 & 0 \\
\hline $\mathrm{C}_{001}$ & -0.1401 & 3.514 & 0 & 0.559 & 0 \\
\hline $\mathrm{C}_{101}$ & -0.1085 & -8.524 & -30.13 & 0 & 0 \\
\hline $\mathrm{C}_{201}$ & -2.065 & -18.05 & 86.99 & 0 & 0 \\
\hline $\mathrm{C}_{301}$ & -2.98 & -4.852 & 5.71 & -2.424 & 0 \\
\hline $\mathrm{C}_{002}$ & 0.01334 & 0.08174 & 0.7274 & -0.002248 & 0 \\
\hline $\mathrm{C}_{102}$ & 0.0213 & 0.5791 & -2.554 & 0 & 0 \\
\hline $\mathrm{C}_{202}$ & 0.1963 & 0.1207 & -0.2169 & 0.1259 & 0 \\
\hline $\mathrm{C}_{003}$ & $-3.704 \times 10^{-4}$ & -0.007021 & 0.01587 & $8.267 \times 10^{-4}$ & $2.413 \times 10^{-4}$ \\
\hline $\mathrm{C}_{103}$ & -0.002957 & 0 & 0.003912 & -0.004141 & $7.107 \times 10^{-5}$ \\
\hline $\mathrm{C}_{010}$ & -1.442 & 1.207 & 76.25 & -8.751 & 0 \\
\hline $\mathrm{C}_{110}$ & 1.047 & -31.68 & -874.1 & 51.96 & 1.905 \\
\hline $\mathrm{C}_{210}$ & 0 & 32.78 & 1636 & -76.51 & -1.761 \\
\hline $\mathrm{C}_{310}$ & 0 & -25.65 & -1040 & 27.69 & 0.3658 \\
\hline $\mathrm{C}_{011}$ & 0 & -2.096 & 4.942 & -1.349 & -0.05227 \\
\hline $\mathrm{C}_{111}$ & 0 & 2.222 & -17.32 & 1.297 & 0 \\
\hline $\mathrm{C}_{211}$ & -1.121 & 0.3871 & 14.97 & -0.09621 & 0 \\
\hline $\mathrm{C}_{012}$ & 0 & -0.004486 & -0.09096 & 0 & 0 \\
\hline $\mathrm{C}_{112}$ & 0.0273 & -0.06669 & 0.2281 & 0 & 0 \\
\hline $\mathrm{C}_{013}$ & 0 & 0.001086 & -0.002971 & $2.192 \times 10^{-4}$ & 0 \\
\hline $\mathrm{C}_{020}$ & 0.6868 & -0.07632 & -21.66 & 3.734 & 2.165 \\
\hline $\mathrm{C}_{120}$ & 0 & 14.32 & 232.4 & -6.438 & 0.6139 \\
\hline $\mathrm{C}_{220}$ & 3.82 & 2.353 & -224.1 & 6.284 & -0.1166 \\
\hline $\mathrm{C}_{021}$ & -0.01898 & 0.3396 & -1.724 & 0.2422 & -0.07307 \\
\hline $\mathrm{C}_{121}$ & -0.1228 & -0.3281 & 3.144 & -0.2272 & 0.005656 \\
\hline $\mathrm{C}_{022}$ & $2.845 \times 10^{-4}$ & $-3.6 \times 10^{-4}$ & $-4.477 \times 10^{-4}$ & 0 & 0 \\
\hline $\mathrm{C}_{030}$ & -0.06543 & 0 & 1.875 & -0.4111 & -0.3134 \\
\hline $\mathrm{C}_{130}$ & 0.1469 & -1.505 & -18.02 & 0.2556 & 0 \\
\hline $\mathrm{C}_{031}$ & 0.00179 & -0.01529 & 0.1523 & -0.009961 & 0.008105 \\
\hline
\end{tabular}

\section{Derivation of the new scheme}

It can be seen from Figs. 1,2 and 3 that $\zeta$ varies with $R i_{\mathrm{B}}$, $\log \left(z / z_{0}\right)$ and $\mathrm{kB}^{-1}$ with remarkable nonlinearity. Specially, when $\mathrm{kB}^{-1}$ is large, $\zeta \sim z_{0}$ relationship can hardly be approximated by a cubic equation at some $R i_{\mathrm{B}}$ values (Fig. 2). Correspondingly, when $z_{0}$ is large, $\zeta \sim z_{0 h}$ also needs a high power series equation to approximate (at least cubic fit is not enough, Fig. 3). In order to reduce the complexity, weakly and strongly stable conditions were treated separately in previous studies (e.g., Launiainen, 1995; Li et al., 2010; WRL12). Analogously, multiple regions are considered for $z_{0}$ and $z_{0 h}$ for the regression of $\zeta=f\left(R i_{\mathrm{B}}, L_{0 \mathrm{M}}, \mathrm{kB}^{-1}\right)$ in this paper. In this way, the complexity of the equations can be reduced and at the same time their accuracy can be maintained. Although the total number of equations is increased due to the division of $z_{0}$ and $z_{0 h}$, the calculation efficiency is still enhanced since the logical judgment of the region according to $z_{0}$ and $z_{0 h}$ values in program codes takes much less time than iterations. The critical issue here is how to divide the $z_{0}$ and $z_{0 h}$ regions in a reasonable way to obtain the smallest number of regions but the highest accuracy. For this purpose, the $z_{0}$ and $z_{0 h}$ are first divided into 13 and 14 sections according to the values of $z / z_{0}$ and $z_{0} / z_{0 h}$, respectively. For $z / z_{0}$, the sections are $10 \sim 20,20 \sim 40,40 \sim 80, \ldots, 10240 \sim 20480$, $20480 \sim 40960$ and $40960 \sim 10^{5}$; for $z_{0} / z_{0 h}$, the sections are $0.607 \sim 1,1 \sim 10,10 \sim 100,100 \sim 10^{3}, 10^{3} \sim 10^{4}$, $\ldots, 10^{11} \sim 10^{12}$ and $10^{12} \sim 1.07 \times 10^{13} . z / z_{0} \in 10 \sim 20$ and $z_{0} / z_{0 h} \in 10^{12} \sim 1.07 \times 10^{13}$ is the region that needs the highest power series equation to approximate. This region is firstly chosen to find a maximum critical value of $\zeta_{c 1}$ that can make the regression

$$
\begin{aligned}
\zeta & =f\left(R i_{\mathrm{B}}, L_{0 \mathrm{M}}, \mathrm{kB}^{-1}\right) \\
& =R i_{\mathrm{B}} \sum C_{i j k} R i_{\mathrm{B}}^{i} L_{0 \mathrm{M}}^{j}\left(L_{0 \mathrm{H}}-L_{0 \mathrm{M}}\right)^{k}
\end{aligned}
$$


Table 6. Similar to Table 3, but for region 4.

\begin{tabular}{|c|c|c|c|c|}
\hline & \multicolumn{4}{|c|}{ Region 4} \\
\hline & Section 1 & Section 2 & Section 3 & Section 4 \\
\hline $\mathrm{C}_{000}$ & 0 & -3.528 & 0 & 0 \\
\hline $\mathrm{C}_{100}$ & 0 & 0 & 0 & 0 \\
\hline $\mathrm{C}_{200}$ & 0 & 0 & 0 & -8.306 \\
\hline $\mathrm{C}_{300}$ & 0 & 0 & 0 & 1.212 \\
\hline $\mathrm{C}_{001}$ & 0 & -0.2511 & -1.018 & 0 \\
\hline $\mathrm{C}_{101}$ & 0 & 0 & 0 & 0 \\
\hline $\mathrm{C}_{201}$ & -6.267 & -10.06 & 0 & 0 \\
\hline $\mathrm{C}_{301}$ & 0 & 0 & 0 & 0 \\
\hline $\mathrm{C}_{002}$ & 0 & 0 & 0 & 0 \\
\hline $\mathrm{C}_{102}$ & 0.09808 & 0.1809 & 0 & 0.0279 \\
\hline $\mathrm{C}_{202}$ & 0 & 0 & 0 & 0 \\
\hline $\mathrm{C}_{003}$ & 0 & 0 & $6.74 \times 10^{-5}$ & $6.853 \times 10^{-4}$ \\
\hline $\mathrm{C}_{103}$ & 0 & 0 & 0.001341 & $-9.314 \times 10^{-4}$ \\
\hline $\mathrm{C}_{010}$ & 0.5961 & 1.375 & -2.404 & 5.253 \\
\hline $\mathrm{C}_{110}$ & 0 & 2.951 & 41.12 & 7.626 \\
\hline $\mathrm{C}_{210}$ & 18.49 & 68.09 & -48.05 & -0.2889 \\
\hline $\mathrm{C}_{310}$ & 34.53 & 0 & 24.94 & 0.06073 \\
\hline $\mathrm{C}_{011}$ & -0.0845 & 0 & -0.06671 & -0.3959 \\
\hline $\mathrm{C}_{111}$ & -0.5106 & -1.361 & 0 & -0.07098 \\
\hline $\mathrm{C}_{211}$ & -0.3543 & 0 & -0.1319 & 0.003821 \\
\hline $\mathrm{C}_{012}$ & 0.004555 & 0.003711 & 0.006818 & 0 \\
\hline $\mathrm{C}_{112}$ & 0 & 0 & 0 & 0 \\
\hline $\mathrm{C}_{013}$ & $-9.402 \times 10^{-5}$ & 0 & $-1.788 \times 10^{-4}$ & 0 \\
\hline $\mathrm{C}_{020}$ & 0.05628 & -0.02359 & 0.5172 & -0.5006 \\
\hline $\mathrm{C}_{120}$ & 0.8075 & 0.305 & -4.023 & -0.7376 \\
\hline $\mathrm{C}_{220}$ & 0 & -3.765 & 2.074 & 0 \\
\hline $\mathrm{C}_{021}$ & 0 & -0.001535 & 0 & 0.04853 \\
\hline $\mathrm{C}_{121}$ & 0.01631 & 0.07098 & 0 & 0.002956 \\
\hline $\mathrm{C}_{022}$ & $-3.8 \times 10^{-5}$ & $-2.577 \times 10^{-4}$ & 0 & 0 \\
\hline $\mathrm{C}_{030}$ & -0.00189 & 0 & -0.0192 & 0.01968 \\
\hline $\mathrm{C}_{130}$ & -0.03755 & 0 & 0.125 & 0.025 \\
\hline $\mathrm{C}_{031}$ & $5.177 \times 10^{-5}$ & 0 & 0 & -0.001897 \\
\hline
\end{tabular}

be within $5 \%$ error when $\zeta \in 0 \sim \zeta_{c 1}$. Here $i, j$, and $k=0,1$, 2 , and 3 , and $i+j+k \leq 4$. $C_{i j k}$ denotes the coefficients from regression. It is found that $\zeta_{c 1}=0.33$ meets this criterion. Then some of the $z_{0}$ and $z_{0 h}$ regions can be merged with each other for the section $\zeta \in 0 \sim 0.33$ and a total of $8 z_{0}-$ $z_{0 h}$ regions are left in the $z_{0}-z_{0 h}$ plane. In other words, the regression error of Eq. (23) can be kept within $5 \%$ in any of the eight regions when $\zeta \in 0 \sim 0.33$ (Table 1). Thus, for these eight regions, it can be found that with the sections divided by the specified critical values $\zeta_{c p}$ (where $p$ is $1,2,3, \ldots$, it indicates the section and its maximum value depends on the $z_{0}-z_{0 h}$ region), the regression error with Eq. (23) can be kept within $5 \%$ for $\zeta \leq 0.5$ and $10 \%$ or $\zeta>0.5$. For a given pair of $z_{0}$ and $z_{0 h}$, the division by $\zeta_{c p}$ can be transformed to $R i_{\mathrm{B} c p}$ :

$R i_{\mathrm{Bcp}}=\sum C_{m n} \log ^{m}\left(L_{0 \mathrm{M}}\right)\left(L_{0 \mathrm{H}}-L_{0 \mathrm{M}}\right)^{n}$.
Here $m, n=0,1,2$, and $m+n \leq 3 ; p$ is $1,2,3, \ldots$, which indicates the section and its maximum value depends on the $z_{0}-z_{0 h}$ region. For region 1 and 7 , the maximum $p$ is 6 , while for other regions it varies between 3 and 5 . The coefficients for Eq. (24) are shown in Table 2. The $R i_{\mathrm{B} c p}$ then cuts the $0-2.5 R i_{\mathrm{B}}$ range into several sections: Sect. 1 is from 0 to $R i_{\mathrm{B} c 1}$, Sect. 2 from $R i_{\mathrm{B} c 1}$ to $R i_{\mathrm{B} c 2}$, and so on. The coefficients for Eq. (23) in each section are given in Tables 3-10. The procedure to obtain these coefficients is summarized below:

1. Divide $z / z_{0}$ into 13 sections: $10 \sim 20,20 \sim 40$, $40 \sim 80, \quad \ldots, \quad 10240 \sim 20480, \quad 20480 \sim 40960$ and $40960 \sim 10^{5}$; divide $z_{0} / z_{0 h}$ into 14 sections: $0.607 \sim 1,1 \sim 10,10 \sim 100,100 \sim 10^{3}, 10^{3} \sim 10^{4}$, $\ldots, 10^{11} \sim 10^{12}$ and $10^{12} \sim 1.07 \times 10^{13}$.

2. Use the region $z / z_{0} \in 10 \sim 20$ and $z_{0} / z_{0 h} \in$ $10^{12} \sim 1.07 \times 10^{13}$ to find $\zeta_{c 1}$. 
Table 7. Similar to Table 3, but for region 5.

\begin{tabular}{|c|c|c|c|c|c|c|}
\hline & \multicolumn{6}{|c|}{ Region 5} \\
\hline & Section 1 & Section 2 & Section 3 & Section 4 & Section 5 & Section 6 \\
\hline $\mathrm{C}_{000}$ & 0 & 0 & -207.7 & -587.1 & 0 & 0 \\
\hline $\mathrm{C}_{100}$ & 0 & 77.11 & 880 & 2726 & 7.886 & 0 \\
\hline $\mathrm{C}_{200}$ & -2.541 & -201.2 & -1550 & -3759 & -0.5889 & 0 \\
\hline $\mathrm{C}_{300}$ & 25.22 & 386.1 & 2201 & 1605 & 0 & 0 \\
\hline $\mathrm{C}_{001}$ & -0.03201 & -0.6831 & 0 & -9.376 & -0.4057 & 0 \\
\hline $\mathrm{C}_{101}$ & 0.1159 & 0 & 11.61 & -4.513 & 0 & 0 \\
\hline $\mathrm{C}_{201}$ & -0.5745 & -7.571 & -96.51 & 70.55 & -0.5218 & 0 \\
\hline $\mathrm{C}_{301}$ & -0.8502 & -8.978 & 0 & -58.16 & 0 & 0 \\
\hline $\mathrm{C}_{002}$ & 0.00208 & 0.07136 & 0.5093 & 0.1711 & 0.01745 & 0 \\
\hline $\mathrm{C}_{102}$ & -0.001668 & 0 & 0.8873 & -0.9373 & -0.01349 & 0 \\
\hline $\mathrm{C}_{202}$ & 0.03737 & 0.3442 & 0.2868 & 1.132 & 0.01468 & 0 \\
\hline $\mathrm{C}_{003}$ & $-1.828 \times 10^{-5}$ & 0 & -0.001909 & -0.006865 & 0 & 0 \\
\hline $\mathrm{C}_{103}$ & $-3.967 \times 10^{-4}$ & -0.003421 & -0.004313 & -0.001126 & 0 & 0 \\
\hline $\mathrm{C}_{010}$ & 0.4298 & 0 & 189.4 & 286.9 & 0 & 0 \\
\hline $\mathrm{C}_{110}$ & -0.03339 & -31.72 & -543.8 & -903.7 & 0 & 0 \\
\hline $\mathrm{C}_{210}$ & 0.05692 & 2.558 & 324 & 407.6 & 0 & 0 \\
\hline $\mathrm{C}_{310}$ & 0 & 0 & -80.25 & 260.2 & 0 & 0.08919 \\
\hline $\mathrm{C}_{011}$ & -0.0233 & 0 & -5.403 & 0 & 0 & 0 \\
\hline $\mathrm{C}_{111}$ & 0 & 2.695 & 14.95 & 14.82 & 0.2908 & 0 \\
\hline $\mathrm{C}_{211}$ & -0.3158 & -2.449 & -1.706 & -26.07 & 0.1992 & 0 \\
\hline $\mathrm{C}_{012}$ & 0 & -0.05044 & -0.4221 & 0.01062 & -0.003177 & 0 \\
\hline $\mathrm{C}_{112}$ & 0.007595 & 0.05465 & 0.164 & 0.2099 & -0.00933 & 0 \\
\hline $\mathrm{C}_{013}$ & 0 & $-6.869 \times 10^{-5}$ & -0.00111 & $9.863 \times 10^{-4}$ & 0 & 0 \\
\hline $\mathrm{C}_{020}$ & 0 & 0.3612 & -53.83 & -44.24 & 0.7321 & 2.053 \\
\hline $\mathrm{C}_{120}$ & 0 & 0 & 89.42 & 98.98 & 2.304 & 0.2534 \\
\hline $\mathrm{C}_{220}$ & 1.793 & 18.63 & 34.6 & 22.67 & -2.456 & -0.2585 \\
\hline $\mathrm{C}_{021}$ & 0.00249 & 0.1236 & 2.704 & -0.01096 & -0.09448 & -0.0338 \\
\hline $\mathrm{C}_{121}$ & -0.05666 & -0.837 & -4.573 & -1.67 & 0.007636 & 0.004269 \\
\hline $\mathrm{C}_{022}$ & 0 & 0.008316 & 0.0718 & -0.01056 & 0.002124 & 0 \\
\hline $\mathrm{C}_{030}$ & 0 & -0.06987 & 4.95 & 2.138 & 0 & -0.3116 \\
\hline $\mathrm{C}_{130}$ & 0.129 & 0.8756 & -3.112 & -4.604 & 0 & 0.1241 \\
\hline $\mathrm{C}_{031}$ & 0 & -0.01959 & -0.3287 & 0.054 & 0 & 0 \\
\hline
\end{tabular}

Method: when $\zeta \in 0 \sim \zeta_{c 1}$, regression with Eq. (23) is kept within $5 \%$ error.

Result: $\zeta_{c 1}=0.33$ found.

3. Use $\zeta_{c 1}=0.33$ to recombine $z / z_{0}$ and $z_{0} / z_{0 h}$ sections defined in step 1 .

Method: variations of combinations of the 13 sections of $z / z_{0}$ and 14 sections of $z_{0} / z_{0 h}$ are tested to minimize the numbers of regions, and regression with Eq. (23) and $\zeta \in 0 \sim 0.33$ is kept within $5 \%$ error.

Result: eight regions found (Table 1).

4. For each of the eight regions, find $\zeta_{c 1}, \zeta_{c 2}, \ldots, \zeta_{c p}, \ldots$

Method: when $\zeta \in 0 \sim \zeta_{c 1}$, or $\zeta_{c 1} \sim \zeta_{c 2}, \ldots$, or $\zeta_{c(p-1)} \sim \zeta_{c p}, \ldots$, regression with Eq. (23) is kept within $5 \%$ error for $\zeta \leq 0.5$ and $10 \%$ error for $\zeta>$ 0.5 .

Result: $\zeta_{c 1}, \zeta_{c 2}, \ldots, \zeta_{\mathrm{cp}}, \ldots$, for each region found.
5. Transfer $\zeta_{c 1}, \zeta_{c 2}, \ldots, \zeta_{c p}, \ldots$, to $R i_{\mathrm{B} c 1}, R i_{\mathrm{B} c 2}, \ldots$ $R i_{\mathrm{B} c p}, \ldots$, with Eq. (24)

Method: for each region, when $R i_{\mathrm{B}} \in 0 \sim R i_{\mathrm{B} c 1}$, or $R i_{\mathrm{B} c 1} \sim R i_{\mathrm{B} c 2}, \ldots$, or $R i_{\mathrm{B} c(p-1)} \sim R i_{\mathrm{B} c p}, \ldots$, regression with Eq. (23) is kept within $5 \%$ error for $\zeta \leq 0.5$ and $10 \%$ error for $\zeta>0.5$.

Result: coefficients of Eqs. (23) and (24) are derived.

The calculation procedure for a given group of $z_{0}, z_{0 h}$ and $R i_{\mathrm{B}}$ is the following: (1) find the region according to $z_{0}$ and $z_{0 h}$ with Table $1 ;$ (2) find the section according to the region and $R i_{\mathrm{B}}$ with Eq. (24) and coefficients in Table 2; and (3) in Tables 3-10 find the coefficients for the particular region and section and use Eq. (23) to calculate $\zeta$. Figure 7 presents the relative error of $\zeta$ with new equations compared with iterated results of $\mathrm{CB} 05$ for various $R i_{\mathrm{B}}$ with $z / z_{0}=10,1000,10^{5}$ and $\mathrm{kB}^{-1}=-0.5,15,30$. With the new equations, the relative error is controlled to be within $10 \%$ for the whole range. 
Table 8. Similar to Table 3, but for region 6 .

\begin{tabular}{|c|c|c|c|c|}
\hline & \multicolumn{4}{|c|}{ Region 6} \\
\hline & Section 1 & Section 2 & Section 3 & Section 4 \\
\hline $\mathrm{C}_{000}$ & 0 & 0.4383 & 0 & -6.744 \\
\hline $\mathrm{C}_{100}$ & -7.864 & 0 & -41.74 & 8.8 \\
\hline $\mathrm{C}_{200}$ & 0 & 0 & 177 & -13.03 \\
\hline $\mathrm{C}_{300}$ & 0 & 0 & -118.2 & 2.203 \\
\hline $\mathrm{C}_{001}$ & -0.02699 & 0 & 0 & -0.1139 \\
\hline $\mathrm{C}_{101}$ & 0.7414 & -4.81 & -4.006 & -0.06103 \\
\hline $\mathrm{C}_{201}$ & -1.114 & 5.094 & -0.5102 & 0.2406 \\
\hline $\mathrm{C}_{301}$ & 0 & -1.159 & 0 & -0.04635 \\
\hline $\mathrm{C}_{002}$ & 0 & 0.04547 & 0 & 0.01341 \\
\hline $\mathrm{C}_{102}$ & 0 & 0 & 0.0567 & -0.002749 \\
\hline $\mathrm{C}_{202}$ & 0 & -0.1233 & 0.1868 & $5.316 \times 10^{-6}$ \\
\hline $\mathrm{C}_{003}$ & 0 & $-5.595 \times 10^{-4}$ & 0.002457 & $-1.434 \times 10^{-4}$ \\
\hline $\mathrm{C}_{103}$ & $1.281 \times 10^{-4}$ & 0.002459 & -0.006455 & 0 \\
\hline $\mathrm{C}_{010}$ & 0.244 & 0 & 0 & 6.511 \\
\hline $\mathrm{C}_{110}$ & 1.743 & 0 & 27.45 & 6.369 \\
\hline $\mathrm{C}_{210}$ & 4.749 & 44.44 & -17.37 & -0.175 \\
\hline $\mathrm{C}_{310}$ & 11.28 & 0 & -7.74 & 0.03419 \\
\hline $\mathrm{C}_{011}$ & 0 & 0 & 0 & -0.3147 \\
\hline $\mathrm{C}_{111}$ & -0.3093 & 0 & 0 & -0.06781 \\
\hline $\mathrm{C}_{211}$ & -0.2208 & -0.6068 & 0.0117 & $-2.026 \times 10^{-4}$ \\
\hline $\mathrm{C}_{012}$ & 0 & -0.005459 & -0.01576 & 0.002444 \\
\hline $\mathrm{C}_{112}$ & 0.003674 & 0 & 0.02102 & $2.616 \times 10^{-4}$ \\
\hline $\mathrm{C}_{013}$ & 0 & 0 & $-1.975 \times 10^{-5}$ & $-5.149 \times 10^{-6}$ \\
\hline $\mathrm{C}_{020}$ & 0.04168 & 0 & -0.1563 & -0.6219 \\
\hline $\mathrm{C}_{120}$ & 0.4341 & 0.9983 & -2.085 & -0.598 \\
\hline $\mathrm{C}_{220}$ & 0.6518 & -2.874 & 0.3443 & 0.002868 \\
\hline $\mathrm{C}_{021}$ & -0.00208 & -0.00152 & 0.03278 & 0.03359 \\
\hline $\mathrm{C}_{121}$ & 0 & 0.01501 & -0.0325 & 0.003178 \\
\hline $\mathrm{C}_{022}$ & $2.895 \times 10^{-5}$ & $3.541 \times 10^{-4}$ & $5.167 \times 10^{-4}$ & $-1.423 \times 10^{-4}$ \\
\hline $\mathrm{C}_{030}$ & 0 & 0.006587 & 0.008163 & 0.02407 \\
\hline $\mathrm{C}_{130}$ & -0.01307 & -0.04253 & 0.0854 & 0.0188 \\
\hline $\mathrm{C}_{031}$ & $1.425 \times 10^{-5}$ & $-3.659 \times 10^{-4}$ & -0.001602 & -0.001167 \\
\hline
\end{tabular}

Especially, when $\zeta \leq 0.5$, the relative error is within $5 \%$ since it happens more often in the real conditions (Fig. 8).

\section{Comparison of the results from $\mathrm{CB} 05$ with five-step iteration, WRL12 and the new scheme}

The maximum and average relative error of $\zeta, C_{\mathrm{M}}$ and $C_{\mathrm{H}}$ calculated from CB05 with five-step iteration, WRL12 and the new scheme are shown in Figs. 8, 9 and 10 for various $\zeta$ with $z / z_{0}=10,1000,10^{5}$ and $\mathrm{kB}^{-1}=-0.5,15,30 . C_{\mathrm{M}}$ and $C_{\mathrm{H}}$ are the transfer coefficients for momentum and sensible heat respectively, and

$C_{\mathrm{M}}=\frac{k^{2}}{\left[\ln \left(\frac{z}{z_{0}}\right)-\psi_{\mathrm{m}}(\zeta)+\psi_{\mathrm{m}}\left(\frac{z_{0}}{z} \zeta\right)+\psi_{\mathrm{m}}^{*}\left(\zeta, \frac{z}{z_{*}}\right)\right]^{2}}$,
$C_{\mathrm{H}}=$ $\frac{k^{2}}{\left[\ln \left(\frac{z}{z_{0}}\right)-\psi_{\mathrm{m}}(\zeta)+\psi_{\mathrm{m}}\left(\frac{z_{0}}{z} \zeta\right)+\psi_{\mathrm{m}}^{*}\left(\zeta, \frac{z}{z_{*}}\right)\right]\left[\ln \left(\frac{z}{z_{0 h}}\right)-\psi_{\mathrm{h}}(\zeta)+\psi_{\mathrm{h}}\left(\frac{z_{0}}{z} \zeta\right)+\psi_{\mathrm{h}}^{*}\left(\zeta, \frac{z}{z_{*}}\right)\right]}$

To speed up the calculation, $\psi_{\mathrm{m}, \mathrm{h}}^{*}\left(\zeta, \frac{z}{z_{*}}\right)$ is not calculated from Eq. (6) but rather from the non-integral equation proposed by De Ridder (2010):

$$
\begin{aligned}
& \psi_{\mathrm{m}, \mathrm{h}}^{*}\left(\zeta, \frac{z}{z_{*}}\right)= \\
& \phi_{\mathrm{m}, \mathrm{h}}\left[\left(1+\frac{v}{\mu z / z_{*}}\right) \zeta\right] \frac{1}{\lambda} \ln \left(1+\frac{\lambda}{\mu z / z_{*}}\right) \exp \left(-\mu z / z_{*}\right),
\end{aligned}
$$

where $\lambda=1.5, \mu=\mu_{\mathrm{m}}=2.59, \mu=\mu_{\mathrm{h}}=0.95$ and $v=0.5$. The relative error for $C_{\mathrm{M}}$ and $C_{\mathrm{H}}$ is calculated from

$$
\Delta C_{\mathrm{M}, \mathrm{H}}=\frac{\left|C_{\mathrm{M}, \mathrm{H}(\mathrm{cal})}-C_{\mathrm{M}, \mathrm{H}(\text { precise })}\right|}{C_{\mathrm{M}, \mathrm{H}(\text { precise })}} \times 100 \% \text {, }
$$


Table 9. Similar to Table 3, but for region 7.

\begin{tabular}{|c|c|c|c|c|c|c|c|}
\hline & & & & Region 7 & & & \\
\hline & Section 1 & Section 2 & Section 3 & Section 4 & Section 5 & Section 6 & Section 7 \\
\hline $\mathrm{C}_{000}$ & -1.412 & -4.502 & -104.2 & 542.4 & 178.4 & 0 & 0 \\
\hline $\mathrm{C}_{100}$ & 6.658 & 40.44 & 136.3 & -1845 & 158.8 & 0 & 0 \\
\hline $\mathrm{C}_{200}$ & -5.68 & 37.42 & 233.3 & 2157 & -480.9 & 0 & 0 \\
\hline $\mathrm{C}_{300}$ & 11.9 & 0 & 0 & 0 & 0 & 0 & 0 \\
\hline $\mathrm{C}_{001}$ & 0.1285 & 0.3067 & 13.8 & -3.691 & -31.49 & 0 & 0 \\
\hline $\mathrm{C}_{101}$ & -0.111 & -5.444 & -37.21 & 3.33 & 47.56 & 0 & 0 \\
\hline $\mathrm{C}_{201}$ & -0.2095 & 2.053 & 10.33 & -45.62 & -4.153 & 0 & 0 \\
\hline $\mathrm{C}_{301}$ & -0.3181 & 0 & 0 & 0 & 0 & 0 & 0 \\
\hline $\mathrm{C}_{002}$ & -0.004693 & 0.05302 & -0.1157 & 0.1434 & 0.3998 & 0 & 0 \\
\hline $\mathrm{C}_{102}$ & 0.004467 & 0 & 0.5542 & 0.4557 & -0.8692 & 0 & 0 \\
\hline $\mathrm{C}_{202}$ & 0.01324 & -0.01586 & -0.2568 & 0.08936 & 0.2504 & 0 & 0 \\
\hline $\mathrm{C}_{003}$ & $6.64 \times 10^{-5}$ & 0 & 0 & 0 & 0 & 0 & 0 \\
\hline $\mathrm{C}_{103}$ & $-2.023 \times 10^{-4}$ & 0 & 0 & 0 & 0 & 0 & 0 \\
\hline $\mathrm{C}_{010}$ & 0.7122 & 1.663 & 16.56 & -263.7 & -37.94 & 0 & 0 \\
\hline $\mathrm{C}_{110}$ & -4.599 & -28.1 & 0 & 677.7 & -147.8 & 20.56 & 0 \\
\hline $\mathrm{C}_{210}$ & 2.705 & -11.02 & -114.4 & -644.2 & 144.7 & -13.42 & 0 \\
\hline $\mathrm{C}_{310}$ & 0 & 0 & 0 & 0 & 0 & 3.002 & 0 \\
\hline $\mathrm{C}_{011}$ & -0.04962 & 0.1172 & -3.238 & 4.44 & 9.904 & -0.5254 & 0.06758 \\
\hline $\mathrm{C}_{111}$ & 0.01147 & 1.979 & 7.578 & -3.037 & -7.914 & 0 & 0 \\
\hline $\mathrm{C}_{211}$ & -0.1621 & -0.7285 & 0 & 10.93 & -2.224 & 0 & 0.003671 \\
\hline $\mathrm{C}_{012}$ & 0.001459 & -0.0293 & 0 & -0.08875 & -0.1235 & 0 & 0 \\
\hline $\mathrm{C}_{112}$ & 0.003514 & 0.01334 & -0.06568 & -0.1436 & 0.1631 & 0 & $-6.967 \times 10^{-4}$ \\
\hline $\mathrm{C}_{013}$ & $-2.01 \times 10^{-5}$ & 0 & 0 & 0 & 0 & $2.282 \times 10^{-4}$ & 0 \\
\hline $\mathrm{C}_{020}$ & 0.003692 & -0.4475 & 0 & 32.93 & 0 & 0 & 0 \\
\hline $\mathrm{C}_{120}$ & 1.299 & 5.193 & -0.1495 & -56.58 & 23.51 & -2.349 & 0.6983 \\
\hline $\mathrm{C}_{220}$ & 0.6516 & 5.593 & 18.12 & 53.14 & -2.645 & 0.628 & -0.1455 \\
\hline $\mathrm{C}_{021}$ & 0 & -0.009728 & 0.167 & -0.951 & -0.7278 & 0.2176 & 0 \\
\hline $\mathrm{C}_{121}$ & -0.03414 & -0.3375 & -0.6387 & 0 & -0.1801 & 0.02067 & 0 \\
\hline $\mathrm{C}_{022}$ & $2.84 \times 10^{-5}$ & 0.00347 & 0.00428 & 0.02119 & 0.008599 & -0.005396 & $-4.282 \times 10^{-4}$ \\
\hline $\mathrm{C}_{030}$ & $6.293 \times 10^{-4}$ & 0 & 0 & 0 & 0 & -0.4148 & 0 \\
\hline $\mathrm{C}_{130}$ & -0.02559 & 0 & 0 & 0 & 0 & 0.02245 & 0 \\
\hline $\mathrm{C}_{031}$ & 0 & 0 & 0 & 0 & 0 & 0.01163 & 0 \\
\hline
\end{tabular}

where $C_{\mathrm{M}, \mathrm{H} \text { (cal) }}$ is calculated with $\zeta_{\text {(cal) }}$ from the three different methods, and $C_{\mathrm{M}, \mathrm{H} \text { (precise) }}$ is calculated with $\zeta_{\text {(precise) }}$ from the ultimate iteration of $\mathrm{CB} 05$.

Maximum error indicates the maximum error for a particular $\zeta$ under various $z_{0}$ and $z_{0 h}$ conditions, while average error is calculated from

Average $\operatorname{Error}(\zeta)=\frac{\int_{-0.5}^{30} \int_{\log (10)}^{\log \left(10^{5}\right)} \operatorname{Error}(\zeta) \mathrm{d} \log \left(\frac{z}{z_{0}}\right) \mathrm{d} \log \left(\frac{z_{0}}{z_{0 h}}\right)}{\int_{-0.5}^{30} \int_{\log (10)}^{\log \left(10^{5}\right)} \mathrm{d} \log \left(\frac{z}{z_{0}}\right) \mathrm{d} \log \left(\frac{z_{0}}{z_{0 h}}\right)}$.

Here "Error $(\zeta)$ " indicates $\Delta \zeta$ or $\Delta C_{\mathrm{M}, \mathrm{H}}$ at a particular $\zeta$, $z_{0}$ and $z_{0 h}$. Although Eq. (29) presents the form of continuous integral, it is actually calculated discretely with interval 0.035 for $\log \left(\frac{z}{z_{0}}\right)$ and 0.1 for $\log \left(\frac{z_{0}}{z_{0 h}}\right)$.

The results indicate that the maximum $\Delta \zeta$ exceeds $50 \%$ when using CB05 with five-step iteration or WRL12, while the averaged $\Delta \zeta$ for the two methods both exceeds $15 \%$. On the contrary, the maximum $\Delta \zeta$ of the new scheme is always smaller than $5 \%$ (when $\zeta \leq 0.5$ ) and $10 \%$ (when $\zeta>0.5$ ), and the average $\Delta \zeta$ is always smaller than $2 \%$ in the whole range. The maximum $\Delta C_{\mathrm{M}}$ from $\mathrm{CB} 05$ with five-step iteration (WRL12) exceeds $50 \%(40 \%)$, and average $\Delta C_{\mathrm{M}}$ exceeds $30 \%(8 \%)$. The maximum $\Delta C_{\mathrm{H}}$ from CB05 with fivestep iteration (WRL12) exceeds $50 \%$ (24\%), and average $\Delta C_{\mathrm{H}}$ exceeds $18 \%(6 \%)$. Comparatively, the new scheme controls the maximum $\Delta C_{\mathrm{M}}\left(\Delta C_{\mathrm{H}}\right)$ to be within $12 \%(9 \%)$ and the average $\Delta C_{\mathrm{M}}\left(\Delta C_{\mathrm{H}}\right)$ within $1 \%(1 \%)$. Table 11 summarizes the characteristics of the four methods.

\section{Summary and conclusions}

Although CB05 provides a way to calculate surface fluxes under stable conditions, its practical usage is confined due 
Table 10. Similar to Table 3, but for region 8 .

\begin{tabular}{|c|c|c|c|c|}
\hline & & Regi & n 8 & \\
\hline & Section 1 & Section 2 & Section 3 & Section 4 \\
\hline $\mathrm{C}_{000}$ & -3.13 & -49.55 & 0 & 0 \\
\hline $\mathrm{C}_{100}$ & 5.26 & 97.14 & 0 & 0 \\
\hline $\mathrm{C}_{200}$ & -29.85 & 352.5 & 10.72 & 0 \\
\hline $\mathrm{C}_{300}$ & 57.04 & -573.4 & 0 & 0 \\
\hline $\mathrm{C}_{001}$ & 0.2176 & 2.052 & 0 & 0 \\
\hline $\mathrm{C}_{101}$ & -0.00898 & -21.41 & 0 & 0 \\
\hline $\mathrm{C}_{201}$ & -1.756 & 13.12 & 0 & 0 \\
\hline $\mathrm{C}_{301}$ & -1.663 & 20.82 & -1.354 & 0 \\
\hline $\mathrm{C}_{002}$ & -0.007271 & 0.1357 & -0.06227 & 0 \\
\hline $\mathrm{C}_{102}$ & 0.0304 & 0.238 & 0 & -0.01477 \\
\hline $\mathrm{C}_{202}$ & 0.05349 & -0.7316 & 0.08799 & -0.001292 \\
\hline $\mathrm{C}_{003}$ & $8.978 \times 10^{-5}$ & -0.003367 & 0.002359 & 0 \\
\hline $\mathrm{C}_{103}$ & $-6.252 \times 10^{-4}$ & 0.006023 & -0.002387 & $3.921 \times 10^{-4}$ \\
\hline $\mathrm{C}_{010}$ & 0.9846 & 14.57 & -0.2492 & 0 \\
\hline $\mathrm{C}_{110}$ & -1.011 & 0 & 19.79 & 0 \\
\hline $\mathrm{C}_{210}$ & 14.45 & 0 & -18.86 & -0.8522 \\
\hline $\mathrm{C}_{310}$ & 4.433 & -54.39 & 9.463 & 0.1065 \\
\hline $\mathrm{C}_{011}$ & -0.05083 & -0.8911 & 0 & 0 \\
\hline $\mathrm{C}_{111}$ & -0.2604 & 1.478 & 0 & 0.374 \\
\hline $\mathrm{C}_{211}$ & -0.2977 & 2.13 & -0.3291 & 0.004036 \\
\hline $\mathrm{C}_{012}$ & 0.001361 & $-9.36 \times 10^{-4}$ & 0 & 0.002528 \\
\hline $\mathrm{C}_{112}$ & 0.00375 & -0.04272 & 0.01369 & -0.006853 \\
\hline $\mathrm{C}_{013}$ & $-1.464 \times 10^{-5}$ & $1.939 \times 10^{-4}$ & $-2.41 \times 10^{-4}$ & $-8.747 \times 10^{-5}$ \\
\hline $\mathrm{C}_{020}$ & -0.004659 & -1.165 & 0 & 0 \\
\hline $\mathrm{C}_{120}$ & 0.6393 & 0 & -1.689 & -0.4307 \\
\hline $\mathrm{C}_{220}$ & 0 & -3.616 & 1.036 & 0.01469 \\
\hline $\mathrm{C}_{021}$ & 0 & 0.06747 & 0.00194 & 0.001642 \\
\hline $\mathrm{C}_{121}$ & 0 & 0.01581 & -0.02897 & 0 \\
\hline $\mathrm{C}_{022}$ & 0 & $-3.126 \times 10^{-4}$ & $8.316 \times 10^{-4}$ & 0 \\
\hline $\mathrm{C}_{030}$ & $8.014 \times 10^{-4}$ & 0.03485 & 0.01694 & 0 \\
\hline $\mathrm{C}_{130}$ & -0.01934 & 0 & 0.06734 & 0.01348 \\
\hline $\mathrm{C}_{031}$ & 0 & -0.001713 & -0.001447 & 0 \\
\hline
\end{tabular}

to the involved iteration process. It has been shown that iteration with five steps will result in large calculation errors, especially when $z / z_{0}$ is small and $\mathrm{kB}^{-1}$ is large, which is common over an urban surface. WRL12 proposed a way to avoid the iteration, but it introduces large error in the calculation procedure so that its calculation accuracy needs to be improved. Through dividing the $z_{0}-z_{0} h$ plane into eight regions, the new scheme develops a group of equations with higher accuracy. The calculation error of $\zeta=$ $f\left(R i_{\mathrm{B}}, L_{0 \mathrm{M}}, \mathrm{kB}^{-1}\right)$ is always controlled to be within $5 \%$ (when $\zeta \leq 0.5$ ) and $10 \%$ (when $\zeta>0.5$ ). The calculation procedure is also simple; for a small $R i_{\mathrm{B}}$ (i.e., $R i_{\mathrm{B}}<R i_{\mathrm{B} c 1}$ ), only one time computation of Eqs. (23) and (24) will suffice. The maximum computation step is six times for Eq. (24) and one time for Eq. (23) when it is in region 1 or 7 and at the same time $R i_{\mathrm{B}}$ is large (i.e., $R i_{\mathrm{B}}>R i_{\mathrm{B} c 6}$ ). Note that the Eq. (24) has only a maximum of eight elements and a minimum of four elements, so the calculation is still efficient.
The new equations involve a large number of parameters, which increase the complexity of coding. However, the effort of coding the new scheme is minimal as compared to its potential gain, which includes the accuracy of the new scheme and the avoidance of iterations. Besides, a compromise can be made between accuracy and complexity. For models that are not interested in high $\mathrm{kB}^{-1}$ values, region 1 and 2 (i.e., $10 \leq z / z_{0} \leq 10^{5}$ and $-0.607 \leq z_{0} / z_{0 h} \leq 100$ ) have provided reasonable coverage (see Garratt, 1992; Launiainen, 1995), and the other six regions can be ignored. For example, in WRF model MM5 surface module, $z_{0 h}=$ $z_{0}$ is assumed during the calculation of frictional velocity (Jiménez et al., 2012). While for models that include urban surface effects, it is better to keep all the regions. Further, CB05 probably is not the final solution for the surface flux calculation under stable stratification. The method used to derive non-iterative equations presented here can be used in future studies to transfer the new iterative algorithm to 
Table 11. Summarization of the characteristics of the four methods. Calculation time is the time each method needs for computing $\zeta$ from $R i_{\mathrm{B}}, z_{0}$ and $z_{0 h}$ in the range $0<R i_{\mathrm{B}} \leq 2.5,10 \leq z / z_{0} \leq 10^{5}$ and $-0.5 \leq \log \left(z_{0} / z_{0 h}\right) \leq 30$ with the interval of 0.01 for $R i_{\mathrm{B}}, 0.035$ for $\log \left(z / z_{0}\right)$ and 0.1 for $\log \left(z_{0} / z_{0 h}\right)$. The calculation is performed on a desktop computer with an Intel Core i5 processor, and note that the calculation time can vary with different computer.

\begin{tabular}{|c|c|c|c|c|}
\hline Method & $\begin{array}{l}\text { Calculation } \\
\text { time }\end{array}$ & $\begin{array}{l}\text { Maximum } \\
\Delta \zeta\end{array}$ & $\begin{array}{l}\text { Average } \\
\Delta \zeta\end{array}$ & Characteristics and suggestion \\
\hline $\begin{array}{l}\text { CB05 with } \\
\text { ultimate } \\
\text { iteration }\end{array}$ & $6260 s$ & N/A & N/A & $\begin{array}{l}\text { Current optimal method, but with high } \\
\text { computational cost. Use this method when } \\
\text { computing power is not an issue. }\end{array}$ \\
\hline $\begin{array}{l}\text { CB05 with } \\
\text { five-step } \\
\text { iteration }\end{array}$ & $3960 \mathrm{~s}$ & exceeds $50 \%$ & exceeds $15 \%$ & $\begin{array}{l}\text { Lower computational cost, but adds more } \\
\text { uncertainty in the calculation procedure } \\
\text { of CB } 05 \text {. }\end{array}$ \\
\hline WRL12 & $261 \mathrm{~s}$ & exceeds $50 \%$ & exceeds $15 \%$ & $\begin{array}{l}\text { Much lower computational cost, but adds } \\
\text { more uncertainty in the calculation procedure } \\
\text { of CB } 05 \text {. }\end{array}$ \\
\hline New equations & $549 \mathrm{~s}$ & $\begin{array}{l}\text { smaller than } \\
5 \%(\text { when } \\
\zeta \leq 0.5) \text { and } \\
10 \% \text { (when } \\
\zeta>0.5)\end{array}$ & $\begin{array}{l}\text { smaller } \\
\text { than } 2 \%\end{array}$ & $\begin{array}{l}\text { Low computational cost, error in the } \\
\text { calculation procedure of CB } 05 \text { is } \\
\text { controlled within } 10 \% \text {. Use this method to } \\
\text { have an optimal compromise between } \\
\text { accuracy and computational cost. }\end{array}$ \\
\hline
\end{tabular}

non-iterative equations. Overall, the new equations cover the full range of $-0.5 \leq \mathrm{kB}^{-1} \leq 30,10 \leq z / z_{0} \leq 10^{5}$ and stable conditions (i.e., $0<R i_{\mathrm{B}} \leq 2.5$ ), and maintain high accuracy and efficiency. It is expected that its usage in climate and weather forecasting models can lead to better performance in surface flux calculation under stable conditions, especially over urban surfaces.

Acknowledgements. This study is supported by China Meteorological Administration under grant GYHY201006024, the National Program on Key Basic Research Project of China (973) under grant 2011CB403501, 2012CB417203 and 2010CB428502, the CAS Strategic Priority Research Program grant XDA05110101, and the National Natural Science Foundation of China under grant 41275022. The first author (Y. Li) is supported by City University of Hong Kong grant no. 7004002. The authors would like to acknowledge P. A. Jiménez, J. Dudhia, J. F. González-Rouco, J. Navarro, J. P. Montávez, E. García-Bustamante, H. Wouters, K. De Ridder and N. P. M. van Lipzig for their two recent papers which made us aware of the deficiency of current surface layer flux schemes. We are grateful to three anonymous reviewers for their careful review and valuable comments, which led to substantial improvement of this manuscript.

Edited by: H. Garny

\section{References}

Beljaars, A. C. M. and Holtslag, A. A. M.: Flux parameterization over land surfaces for atmospheric models, J. Appl. Meteorol., 30, 327-341, 1991.

Businger, J. A.: Transfer of momentum and heat in the planetary boundary layer,in Proceedings of the symposium on the Arctic heat budget and atmospheric circulation, 305-331, 1966.

Businger, J. A., Wyngaard, J. C., Izumi, Y., and Bardley, E. F.: Fluxprofile relationships in the atmospheric surface layer, J. Atmos. Sci., 28, 181-189, 1971.

Chen, F. and Dudhia, J.: Coupling an advanced land surfacehydrology model with the Penn State-NCAR MM5 modeling system. Part I: Model implementation and sensitivity, Mon. Weather Rev., 129, 569-585, 2001.

Cheng, Y. G. and Brutsaert, W.: Flux-profile relationships for wind speed and temperature in the stable atmospheric boundary layer, Bound.-Lay. Meteorol., 114, 519-538, 2005.

De Bruin, H. A. R., Ronda, R. J., and Van De Wiel, B. J. H.: Approximate solutions for the Obukhov length and the surface fluxes in terms of bulk Richardson numbers, Bound.-Lay. Meteorol., 95, 145-157, 2000.

De Ridder, K.: Bulk transfer relations for the roughness sublayer, Bound.-Lay. Meteorol., 134, 257-267, 2010.

Dyer, A. J.: The turbulent transport of heat and water vapour in an unstable atmosphere, Q. J. Roy. Meteorol. Soc., 93, 501-508, 1967.

Dyer, A. J.: A review of flux-profile relationships, Bound.-Lay. Meteorol., 7, 363-372, 1974.

Fairall, C. W., Bradley, E. F., Rogers, D. P., Edson, J. B., and Young, G. S.: Bulk parameterization of air-sea fluxes for TOGACOARE, J. Geophys. Res., 101, 3747-3764, 1996.

Fairall, C. W., Bradley, E. F., Hare, J. E., Grachev, A. A., and Edson, J. B.: Bulkparameterization of air-sea fluxes: updates and 
verification for the COARE algorithm, J. Climate, 16, 571-591, 2003.

Garratt, J. R.: The atmospheric boundary layer, Cambridge University Press, Cambridge, 1992.

Grachev, A. A. and Fairall, C. W.: Dependence of the MoninObukhov stability parameter on the bulk Richardson numberover the ocean, J. Appl. Meteorol., 36, 406-414, 1997.

Grachev, A. A., Andreas, E. L., Fairall, C. W., Guest, P. S., and Persson, P. O. G.: SHEBAflux-profile relationships in the stable atmospheric boundary layer, Bound.-Lay. Meteorol., 124, 315333, 2007.

Grachev, A. A., Andreas, E. L., Fairall, C. W., Guest, P. S., and Persson, P. O. G.: Thecritical Richardson number and limits of applicability of local similarity theory in the stable boundary layer, Bound.-Lay. Meteorol., 147, 51-82, 2013.

Guo, X. and Zhang, H.: A performance comparison between nonlinear similarity functions in bulk parameterization for very stable conditions, Environ. Fluid. Mech., 7, 239-257, 2007.

Högström, U.: Review of some basic characteristics of the atmospheric surface layer, Bound.-Lay. Meteorol., 78, 215-246, 1996.

Holtslag, A. A. M. and de Bruin, H. A. R.: Applied modelling of the nighttime surface energy balance over land, J. Appl. Meteorol., 22, 689-704, 1988.

Janjić, Z. I.: The step-mountain eta coordinate model: further developments of the convection, viscous sublayer and turbulence closure schemes, Mon. Weather Rev., 122, 927-945, 1994.

Janjić, Z. I.: The surface layer in the NCEP Eta Model. Eleventh conference on numerical weather prediction, Norfolk, VA, 1923 August 1996, Am. Meteorol. Soc., Boston, MA, 354-355, 1996.

Jiménez, P. A., Dudhia, J., González-Rouco, J. F., Navarro, J., Montávez, J. P., and García-Bustamante, E.: A revised scheme for the WRF surface layer formulation, Mon. Weather Rev., 140, 898918, 2012.

Launiainen, J.: Derivation of the relationship between the Obukhov stability parameter and the bulk Richardson number for fluxprofile studies, Bound.-Lay. Meteorol., 76, 165-179, 1995.

Li, Y., Gao, Z., Lenschow, D. H., and Chen, F.: An improved approach for parameterizing surface-layer turbulent transfer coefficients in numerical models, Bound.-Lay. Meteorol., 137, 153$165,2010$.

Louis, J. F.: A parametric model of vertical eddy fluxes in the atmosphere, Bound.-Lay. Meteorol., 17, 187-202, 1979.

Monin, A. S. and Obukhov, A. M.: Dimensionless characteristics of turbulence in the surface layer of the atmosphere, Trudy. Geofiz. Inst. Akad. Nauk. SSSR, 24, 163-187, 1954.
Nakanishi, M. and Niino, H.: An improved Mellor-Yamada Level3 model: Its Numerical Stability and Application to a Regional Prediction of Advection Fog, Bound.-Lay. Meteorol., 119, 397407, 2006.

Paulson, C. A.: The mathematical representation of wind speed and temperature in the unstable atmospheric surface layer, J. Appl. Meteorol., 9, 857-861, 1970.

Poulos, G. S., Blumen, W., Fritts, D. C., Lundquist, J. K., Sun, J., Burns, S. P., Nappo, C.,Banta, R., Newsom, R., Cuxart, J., Terradellas, E., Balsley, B.,and Jensen, M.: CASES-99: A Comprehensive Investigation of the Stable Nocturnal Boundary Layer, B. Am. Meteorol. Soc., 83, 555-581, 2002.

Sanz Rodrigo, J. and Anderson, P. S.: Investigation of the stable atmospheric boundary layer at Halley Antarctica, Bound.-Lay. Meteorol., 148, 517-539, 2013.

Sarkar, A. and De Ridder, K.: The urban heat island intensity of Paris: a case study based on a simple urban surface parametrization, Bound.-Lay. Meteorol., 138, 511-520, 2010.

Sharan, M. and Kumar, P.: Estimation of upper bounds for the applicability ofnon-linear similarity functions for non-dimensional wind and temperature profiles inthe surface layer in very stable conditions, P. Roy. Soc. A., 467, 473-494, 2011.

Skamarock, W. C., Klemp, J. B., Dudhia, J., Gill, D. O., Barker, D. M., Wang W., and Powers, J. G.: A description of the advanced research WRF version 3, NCAR Technical Note, 2008.

Song, Y.: An improvement of the Louis scheme for the surface layer in an atmospheric modelling system, Bound.-Lay. Meteorol., 88, 239-254, 1998.

Sorbjan, Z.: Gradient-based scales and similarity laws in the stable boundary layer, Q. J. Roy. Meteorol. Soc., 136, 1243-1254, 2010.

Sorbjan, Z. and Grachev, A. A.: An evaluation of the flux-gradient relationship in the stable boundary layer, Bound.-Lay. Meteorol., 135, 385-405, 2010.

Sugawara, H. and Narita, K.: Roughness length for heat over an urban canopy, Theor. Appl. Climatol., 95, 291-299, 2009.

Wouters, H., De Ridder, K., and van Lipzig, N. P. M.: Comprehensive Parametrization of Surface-Layer Transfer Coefficients for Use in Atmospheric Numerical Models, Bound.-Lay. Meteorol., 145, 539-550, 2012.

Wyngaard, J. C. and Coté, O. R.: Cospectral similarity in the atmospheric surface layer, Q. J. Roy. Meteorol. Soc., 98, 590-603, 1972.

Yang, K., Tamai, N., and Koike, T.: Analytical solution of surface layer similarity equations, J. Appl. Meteorol., 40, 1647-1653, 2001. 